\title{
1 Integration of fuzzy logic and image analysis for the detection of 2 gullies in the Calhoun Critical Zone Observatory using airborne 3 LiDAR data
}

5 Leonardo V. Noto ${ }^{1}$, Satish Bastola ${ }^{2}$, Yannis G. Dialynas ${ }^{2}$, Elisa Arnone ${ }^{1}$, Rafael L. Bras ${ }^{2}$

6 [1] Dipartimento di Ingegneria Civile, Ambientale, Aerospaziale, dei Materiali, Università 7 degli Studi di Palermo, Palermo, ITALY

8 [2] School of Civil and Environmental Engineering, Georgia Institute of Technology, Atlanta, 9 GA, USA

Correspondence to: L.V. Noto (leonardo.noto@unipa.it)

\section{Abstract}

14 The entire Piedmont of the Southeastern United States, where the Calhoun Critical

15 Zone Observatory (CCZO) is located, experienced one of the most severe erosive events of

16 the last two centuries. Forested areas were cleared to cultivate cotton, tobacco, and other

17 crops during the nineteenth and early twentieth century and these land use changes,

18 together with intense rainfalls, initiated deep gullying. An accurate mapping of these

19 landforms is important since, despite some gully stabilization and reforestation efforts,

20 gullies are still major contributors of sediment to streams. Mapping gullies in the CCZO area

21 is hindered by the presence of dense canopy, which precludes the identification through

22 aerial photogrammetry and other traditional remote sensing methods. Moreover, the wide

23 spatial extent of the gullies makes the identification and characterization of entire gullies

24 through field surveys a very large and expensive proposition.

25 This work aims to develop a methodology to automatically detect and map gullies 26 based on a set of algorithms and morphological characteristics retrieved by very high 
27 resolution (VHR) imagery. A one-meter resolution LiDAR Digital Elevation Model (DEM) is

28 used to derive different morphometric indices, which are combined by using spatial 29 analysis methods and fuzzy logic rules, building up a tool able to automatically identify 30 gullies. This spatial model has been calibrated using, as reference, the perimeters of two

31 relatively large gullies that have been measured during a recent field survey. The entire

32 procedure aims to provide estimates of gully erosion patterns, which characterize the 33 entire CCZO area, and to develop an objective method to measure characteristic features of 34 gullies (i.e., depth and volume).

\section{Introduction}

37 Agricultural practices are known to be very important causes of accelerated soil erosion.

38 Among the different types of soil erosion, gully erosion can be considered as a form of 39 accelerated erosion. Gullies are fairly steep-sided channels which experience ephemeral 40 flows mainly during heavy or prolonged rainfall periods. The presence of significant gully 41 erosive processes may affect soil productivity, restrict land use and lead to an increase of 42 risk to infrastructure.

43 Poesen et al. (2003) highlighted that gully erosion is an important soil degradation 44 process in a range of environments, causing considerable soil losses and producing large 45 volumes of sediment. Moreover, gullies efficiently move runoff and sediment from uplands 46 to lowlands and aggravate offsite effects of soil erosion. Gully erosion processes may 47 significantly degrade soils and have detrimental effects on water quality and sediment 48 discharge in a catchment. Data collected from different parts of the world by Poesen et al. 49 (2003) highlight the dramatic importance of gully erosion processes; they show that the 
50 associated soil loss rates may represent a range of $10 \%$ to $94 \%$ of the total sediment yield

51 caused by water erosion (Poesen, 2011).

52 Some of the major causes of gullying can be related to inappropriate cultivation and 53 irrigation, overgrazing, logging, road construction and urbanization. Other drivers of

54 gullying are concentrated runoff from steep lands flowing into cleared drainage

55 depressions, unstable soils in drainage lines, and elevated runoff caused by factors such as

56 low levels of tree cover and poor soil infiltration (Daba et al., 2003; Valentin et al., 2005).

57 Identifying gullies requires a very precise definition of such landforms. Peasley and

58 Taylor (2009) defined gully erosion as a process that causes the removal of soil through

59 concentrated surface runoff and characterized by incised channels greater than $30 \mathrm{~cm}$, and

60 generally restricted to streams with order lower than three. Poesen et al. (2003) classified

61 gullies as permanent gullies, ephemeral gullies, and bank gullies. Permanent gullies are

62 channels deep enough (ranging from 0.5-25-30 m; Soil Science Society of America, 2001)

63 not easily ameliorated with ordinary tillage practices; ephemeral gullies, which have smaller

64 channels than permanent gullies, are initiated by concentrated flow and have channel

65 erosion larger than rill erosion but less than classical gully erosion; and bank gullies are

66 developed wherever concentrated runoff crosses an earth bank.

67 Morphometric characteristics of gullies including shape, size and growth pattern are

68 influenced by soil factors such as erodibility and the occurrence of fragipans within the

69 profile (Moore et al., 1988). Other influences are topography such as the upstream

70 contributing area (Poesen and Govers, 1990), bed and slope steepness (Foster, 1986;

71 Poesen and Govers, 1990; Poesen, 1993) and by agronomic practices. Even if some attempts 
72 have been made to provide a systematic classification of such characteristics relative to the

73 different types of gullies and their controlling factors (e.g. topography, soil type, land use,

74 hydrology) in different environments, there is still no consensus on single definitions, and

75 many aspects of the classification of gullies remain quite vague (i.e. the distinction between

76 a large gully and an ephemeral river channel).

77 While gullies have been mapped through conventional field surveying, this task is an 78 intensive and expensive activity. Identifying the edges of relatively large gullies can be 79 difficult, even from in-situ observations. Accurate and spatially extensive information on 80 gully location and extent at an appropriate spatial scale is essential to take measures in 81 reducing sediment movement (Poesen et al., 2003).

82 The definition of gullies can be achieved in terms of morphological characteristics. Since 83 the most important source of quantitative morphometry is provided by Digital Elevation 84 Models (DEMs), they are a popular choice for mapping gullies. So far, one of the main 85 historical obstacles for using of DEMs for mapping gullies at landscape scale has been the 86 relatively low resolution that characterized past DEMs. The recent widespread availability 87 of very high resolution (VHR) imagery has drastically changed this constraint, leading to a 88 remarkable growth in the availability of terrain information with notable advantages over 89 traditional surveying techniques (Slatton et al., 2007), and providing a basis for the 90 development of new methodologies for analyzing Earth surfaces (Tarolli et al., 2009).

91 Among VHR products, the most promising data source for identifying gully systems is 92 airborne LiDAR data (Roering et al., 2013) because of its fine resolution, high accuracy (i.e. 93 submeter resolution) and its capability to derive bare ground surface topographic data by 
94 automatically filtering vegetation and other objects on the surface (Tarolli, 2014). Extensive

95 LiDAR datasets are now available in several countries. Previous efforts have demonstrated

96 the ability of airborne LiDAR to accurately represent gully cross-sectional forms (Jackson et

97 al., 1988; Ritchie et al., 1994), to map the location of gully heads (Hancock and Evans, 2006),

98 and to characterize gully networks (James et al., 2007).

99 Different procedures have been developed to operate on these high resolution DEM data.

100 They can be roughly classified as a) pixel-based (or using per-pixel approach) and b) object-

101 based (i.e. using object based image analysis - OBIA). The former approach encompasses all

102 work based on the classical approach of map algebra where the pixel is the main spatial

103 primitive with a "pixel-centric" view typical of traditional remote sensing and GIS science

104 (Martinez-Casasnovas, 2003; James et al., 2007; Evans and Lindsay 2010; Perroy et al.,

105 2010; Baruch and Filin, 2011; Höfle et al., 2013; and Castillo et al., 2014); whereas the latter

106 approach is based on the analysis of spatial data based on the concept of the image object

107 (see Blaschke, 2010; Blaschke et al., 2014; Eustace et al., 2009; Shruthi et al., 2011;

108 Johansen et al., 2012; d'Oleire-Oltmanns et al., 2014).

109 One of the earlier efforts based on the pixel-centric approach is that of James et al. (2007)

110 who mapped gullies, and headwater streams of the Sumter National Forest (SNF) of the

111 South Carolina Piedmont (southeastern USA) under dense forest canopy using a $2 \mathrm{~m}$

112 resolution LiDAR DEM. The authors did not propose a unified and automated method to

113 extract gullies from the DEM but rather demonstrated the use of the upstream contributing

114 area with fixed threshold in identify gullies by comparing it with other methods (i.e.

115 contour crenulations). However they suggested that the use of LiDAR DEM can

116 underestimate gully depths and overestimate widths because of shading of gully floors from 
117 off nadir beam paths, or potentially because of removal of information during pre118 processing of the LiDAR DEM.

119 Evans and Lindsay (2010) developed a pixel-based approach to extracting gully maps 120 using a 2 m LiDAR DEM. A combination of areas of low difference from mean elevation and

121 high positive plan curvature was used to detect the position of gullies. Moreover, the 122 authors analyzed the effect of the kernel size of the indices, highlighting that the optimal 123 size has to be greater or equal to the width of the gullies (i.e. $30 \mathrm{~m}$ for the study area). Gully 124 depth was estimated for a particular grid cell by subtracting an estimate of 'pre-gully' 125 elevation, obtained by a weighted linear interpolation method specifically derived by the 126 authors, from the elevation of the grid cell in the LiDAR DEM.

127 An automatic GIS-based detection and delineation of gully channels has been proposed 128 by Höfle et al. (2013) for a high altitude and remote cushion peatland in the Peruvian 129 Andes, using a LiDAR DEM. The method combines breaklines detection and sink filling 130 based on a hydrologically conditioned DEM (i.e. a DEM without sinks). This method is able, 131 according to the authors, to delineate landforms even if gully bottoms have only partly been 132 captured, due to topographic occlusion of the laser scan.

133 Castillo et al. (2014) implemented and tested an automated GIS-based procedure built on 134 normalized topographic indices for gully mapping in Spain using topographic data of a 135 variety of scales, ranging from the rill to the badland landscapes. The authors demonstrated 136 that the joint use of normalized elevation and slope as detection variables and of other 137 topographic variables for filtering purposes was an efficient and scale-independent 138 approach for gully mapping. Since resolution plays an important role in the analysis of 
139 DEMs and the accuracy of associated derivatives, the authors demonstrated that the

140 optimal window size of the normalized indices was in the order of twice the maximum

141 width of the gully.

142 While the performance of the traditional pixel-based approaches depends entirely on the

143 information of single pixels and the direct neighborhoods, the second group of methods,

144 based on the paradigm of Object-based Image analysis (OBIA or GEOBIA when the

145 GEOgraphical aspect is taken into account), still exploit pixel information but through a

146 procedure of pixels grouping. Additional features such as homogeneity of the region and

147 within-region variation can be addressed. The regions are typically generated through

148 using one or more criteria of homogeneity in one or more dimensions (d'Oleire-Oltmanns et

149 al., 2014).

150 Eustace et al. (2009) pioneered the detection of gullies based on the GEOBIA paradigm.

151 The authors used a semi-automated object oriented classification method to detect and map

152 gully extent and volume in eastern Australia. Although the method provided promising

153 results when compared to other VHR data sources, the study did not use field data to verify

154 the volumetric gully estimates.

155 Shruthi et al. (2011) presented an approach based on the use of 1m DEM derived from

156 the IKONOS satellite data. The DEM was hydrologically corrected using the software SAGA

157 (System for Automated Geoscientific Analyses) GIS to obtain terrain derivatives such as slope,

158 flow direction, specific catchment area and sub-watersheds, which were used, along with

159 the DEM, as input layers for OBIA. The approach was promising, as the method could 
160 identify the finer gully edges within the complex gully system better than a manual 161 digitization method, which is highly subjective.

162 Following the work of Eustace et al. (2009), Johansen et al. (2012) applied object-based 163 approach for mapping the spatial extent and volume of gullies in northern Australia using 164 LiDAR DEM data from 2007 and 2010 with a spatial resolution of $0.5 \mathrm{~m}$. Gully edges were 165 detected using a min/max filter with a 2D kernel size of $5 \times 5$. A complex procedure based 166 on a series of image segmentation was applied based on the DEM and slope layers to create 167 objects on both the outside and inside of the gullies, and to extract gullies from the DEM.

168 Finally, recent work by d'Oleire-Oltmanns et al. (2014) made use of four bands from the 169 QuickBird-2 satellite imagery (0.6 m resolution) instead of DEM, to detect gullies in the 170 region of Taroudannt, Morocco. After initial image segmentation, a hierarchical multi-scale 171 approach, with multiresolution segmentation, was used to create the objects (i.e. gullies) at 172 each level. The accuracy of gullies extraction was assessed using manually delineated 173 reference data collected from several field campaigns and resulted in an overall accuracy of $17462 \%$.

175 This paper aims to evaluate the combination of different simple morphometric indices to 176 characterize the morphological properties of gullies in a fuzzy logic framework, which is a 177 novelty in this field. The fuzzy logic framework is used in the Calhoun Critical Zone 178 Observatory (CCZO) where several gullies have been observed and mapped by others (e.g. 179 James et al., 2007) and where a very high resolution (i.e., $1 \mathrm{~m}$ ) LiDAR DEM is now available. 180 The proposed procedure tries to automate the mapping of gullies and of the resulting gully 181 erosion patterns, which characterize the Calhoun area. The objectives of the paper are to 
182 develop and assess an automated procedural chain of different algorithms to detect gullies

183 based on their morphological characteristics retrieved from LiDAR DEM, and to develop

184 and evaluate a method to measure main characteristics of gullies (i.e., depth and volume) :

185 moreover, an overall assessment of the gully sediment yield at watershed scale is carried

186 out with the aim to verify the consistency of gully erosion estimates provided by the

187 presented methodology.

\section{Study area and LiDAR Dataset}

190 The CCZO is located in the USA's Southern Piedmont that extends from Virginia to

191 Alabama, and is part of the CZO project, i.e. a project funded by National Science Foundation

192 for the observation and the study of nine US natural "critical zones". The Calhoun

193 experimental forest has a history that involves some of the most severe agricultural land

194 and water degradation in the nation (Trimble, 1974). By the mid-20th century, nearly 18

$195 \mathrm{~cm}$ of soil over more than 10 million ha were estimated to have been lost to erosion. Rivers

196 carried enormous sediment loads and cultivation-based crops were no longer viable. A

197 large numbers of farmers had abandoned the land when erosion and nutrient depletion

198 became so severe that the land could no longer support cotton or tobacco crops. An

199 estimated $200 \mathrm{~km}^{2}$ of actively eroding gullies and severely eroded soils initially dissected

200 the Sumter National Forest. By the late 20th century, the eroded and often abandoned

201 Piedmont farmland had been extensively reforested, motivating many to adopt the

202 perspective that the degraded land had been restored in a matter of decades by a process 
203 known as "old-field succession". Detailed information about this area is provided in the 204 work of James et al. (2007).

205 The LiDAR data were collected as part of the CCZO project during a 2-day campaign 206 (August 5, 2014 - August 6, 2014), with an Optech Gemini Airborne Laser Terrain Mapper 207 (ALTM) (National Center for Airborne Laser Mapping, 2014). LiDAR point measurements 208 were filtered into returns from vegetation and bare ground using the TerraSolid software 209 (TerraScan Version 14.013) classification routines and algorithms obtaining a 1m DEM with 210 horizontal datum NAD83, vertical datum NAVD88 and projection UTM Zone 17N. The 211 absolute vertical accuracy has not been evaluated since no ground checkpoints were 212 collected. For this reason a small vertical bias $(<0.15 \mathrm{~m})$ in the elevations of the final point 213 cloud and DEM may exist with respect to NAVD88 (National Center for Airborne Laser 214 Mapping, 2014). This accuracy usually degrades on steep terrain and under canopy. 215 Additionally, a 1 m DSM (Digital Surface Model), which takes into account also the canopy, 216 has been produced.

217 The LiDAR data cover an area consisting of a $13 \mathrm{~km} \times 15 \mathrm{~km}$ rectangle $\left(195 \mathrm{~km}^{2}\right)$ located 218 at $40 \mathrm{~km} \mathrm{SE}$ of Spartanburg, South Carolina (Figure 1). Within this vast area, two smaller 219 subareas have been identified to test and apply the proposed method. The first, called 220 SUBAREA-A (Figure 2a), covers an area of approximately $1 \mathrm{~km}^{2}$ where two gullies have 221 been identified and mapped. The associated perimeters were defined during a field survey, 222 carried out in June 2015, through a visual identification of the change in slope at the top of 223 the gully walls (i.e. the point where the relatively flat gully margins starts to slope into the 224 gully) and allowed for the calibration of the method aimed to the gully identification. The 225 perimeter coordinates were acquired using a differential GPS total station (Topcon Hiper 
226 Lite +) in RTK (real Time Kinematic) mode with a horizontal accuracy of about $25 \mathrm{~cm}$. It is

227 important to point out that, since the identification of gully edges is not always an easy task,

228 especially when faced with cross sections with intricate shapes and diffuse limits (Casalí et

229 al., 2015), a certain degree of uncertainty related to their identification and greater than the

230 horizontal accuracy of the survey has to be taken into account.

231 The entire procedural chain here proposed has been applied to the second subarea

232 (SUBAREA-B, with an area of $4.3 \mathrm{~km}^{2}$ - Figure 2b), which corresponds to the Holcombe's

233 Branch watershed, a tributary of Tyger river; this subarea was chosen since it includes

234 several gullies, and represents a focal area of the CCZO project (Dialynas et al., 2016).

\section{Methods}

237 The methodology builds on the use of four different morphometric indices able to detect 238 the presence of specific landforms, which can be interpreted as part of a gully. In particular 239 two different sets of indices were used in this study: one index to detect the internal part of 240 gully (gully bottom) and three indices to identify the gully boundary (gully edge) (Noto et 241 al, 2015).

\section{$242 \quad \underline{3.1}$ Morphometric indices}

\section{$243 \quad 3.1 .1$ TPI for gully bottom}

244 The first index, the Topographic Position Index (TPI) (Guisan et al. 1999), is also known 245 as DFME (Difference From Mean Elevation - Gallant and Wilson, 2000) and has been used to 246 detect gullies by Evans and Lindsay (2010). The TPI is defined as the difference between a 247 cell elevation value $z$ and the average elevation $\bar{z}_{\alpha}$ of the neighborhood around that cell 
248 within the kernel of size $\alpha$. Positive values mean the cell is higher than its surroundings

249 while negative values mean it is lower. If $z$ is significantly higher than $\bar{z}_{\alpha}$, then the cell is

250 likely at or near the top of a hill or ridge. Significantly low values of $z$ (and then of TPI)

251 suggest the cell is at or near the bottom of a valley.

252 The normalized TPI was used here, obtained by dividing by the mean value of elevation 253 within the used kernel ( $n$ TPI):

254

$$
n T P I=\frac{\mathrm{z}-\overline{\mathrm{z}}_{\alpha}}{\overline{\mathrm{z}}_{\alpha}}
$$

255 The $n$ TPI was derived creating a specific function in GRASS GIS starting from the existing 256 r.neighbors function; this function requires the definition of kernel size $\alpha$ among the other 257 optional inputs.

\subsubsection{Maximum curvature for gully edge}

260 Surface curvature, which is the second spatial derivative of the terrain elevations, is one 261 of the basic terrain parameters widely used in terrain analysis (Evans, 1979) and landform 262 classification (Schmidt and Hewitt, 2004). The profile curvature (i.e., curvature of the 263 surface in the steepest direction) and plan curvature (i.e., curvature of the contour) are the 264 most frequently calculated topographic attribute (Gallant and Wilson, 2000).

265 Among the different methods used to derive curvature, Evans (1979) suggested two 266 measures of minimum (i.e. concavity) and maximum curvature (i.e. convexity). Maximum 267 curvature has been adopted as index of gully edge presence since the gully edges can be 268 assimilated to convex slope breaks forming ridges (Tarolli et al., 2012). 
269 The maximum curvature was used as index for gully detection here, and was derived 270 from the DTM by applying methods developed by Wood (1996), which allows for a

271 multiple-scale parameterization by generalizing the calculation for different kernel sizes.

272 Following this approach a local surface is approximated using a bivariate quadratic function

$$
z=c_{1} x^{2}+c_{2} y^{2}+c_{3} x y+c_{4} x+c_{5} y+c_{6}
$$

274 where $z$ is the elevation, $x$ and $y$ are the planar coordinates and $c_{\mathrm{i}}(\mathrm{i}=1, \ldots, 6)$ are the quadric

275 surface coefficients. This surface allows for the maximum curvature assessment using its 276 coefficients:

$$
c_{\max }=\alpha \mathrm{D}\left[-c_{1}-c_{2}+\sqrt{\left(c_{1}-c_{2}\right)^{2}+c_{3}^{2}}\right]
$$

278 where $\alpha$ is the size of the moving kernel and $D$ is the DEM resolution. The maximum

279 curvature was derived, whithin GRASS GIS, using r.param.scale function, which requires the 280 definition of the size of the moving kernel $\alpha$.

\subsubsection{MinMax index for gully edge}

283 The second index used to detect the edges of gullies is a focal map algebra function (i.e. 284 filter) defined by Gallant and Wilson (2000) as ER (Elevation Range) and used by Johansen 285 et al. (2012). This filter, here defined as MinMax operator, calculates the difference between 286 the maximum and minimum values of elevation $z$ present in a moving kernel of size $\alpha$

$$
\operatorname{MinMax}=\max _{\alpha}(z)-\min _{\alpha}(z)
$$


High values of this index may highlight the presence of strong discontinuities in the terrain surface (i.e. gully edge). The index was here normalized through the mean value of 290 elevation $\overline{\mathrm{z}}_{\alpha}$ of the kernel of size $\alpha$.

$$
n \operatorname{MinMax}=\frac{\max _{\alpha}(z)-\min _{\alpha}(z)}{\bar{z}_{\alpha}}
$$

292 Similarly to the $n$ TPI, $n$ MinMax was derived creating a specific function in GRASS GIS 293 starting from the existing r.neighbors function and also in this case kernel size $\alpha$ is the only 294 input parameter.

\subsubsection{Vosselman index for the detection of gully edges}

297 This index is a filter derived by Vosselman (2000) and Vosselman and Maas (2001) to 298 detect anomalies in the elevation of a LiDAR dataset usually originating from the pulses 299 reflected e.g., by buildings, trees, cars, electricity wires, and other aboveground objects. The 300 Vosselman filter is based on the observation that a large difference in elevation between 301 two nearby points is unlikely to be attributed to a steep slope in the terrain. Likely, the 302 higher point among the two is not a ground point. Clearly, for some difference in elevation, 303 the probability that the higher point could be a ground point decreases if the distance 304 between the two points decreases. Therefore, the author explicitly defined the "acceptable" 305 difference in elevation between two points as a function of the distance between the points: $306 \Delta \mathrm{z}_{\max }(d)$. 
307 For example, if the measurements are free from errors, the maximum acceptable level of differences is the function of threshold slope $(\beta)$ and the distance $d$ between points

$$
\Delta \mathrm{z}_{\max }(d)=\beta d
$$

310 In the usual case of noisy measurements, the author suggested to add a confidence

311 interval to the criterion. If one would allow that $5 \%$ of the terrain points with a standard 312 deviation $\sigma$ may be rejected, the filter function becomes

$$
\Delta \mathrm{z}_{\text {max }}(\mathrm{d})=\beta \mathrm{d}+1.652 \sigma
$$

314 This filter, which was used here to detect the gully boundaries as anomalies of the 315 terrain, provides, as outcome, a Boolean index (i.e. only 0 and 1 values are allowed, where 1

316 means presence of anomalies - boundaries). The central pixel of the moving kernel is

317 classified as gully cell if there exists at least one pixel within the kernel with an elevation

318 difference larger than the maximum acceptable level of differences for a given distance. A 319 terrain slope threshold $\beta$ is used to modify the filter function to match the overall slope in 320 the study area and the confidence interval can be used to reject outliers during 321 computation; besides the slope threshold, the filter requires also the kernel size as input.

\section{$323 \quad 3.2$ Description of gully detection algorithm}

324 The first step of the algorithm for the automatic detection of gullies is the derivation of 325 the aforementioned indices (nTPI, $c_{\max }$, nMinMax and Vosselman index). All these indices 326 require a careful definition of a support scale (i.e. the kernel size $\alpha$ ). Moreover in the case of 327 Vosselman index, the threshold slope has to be defined as well. 
328 For the $n T P I$ index, Evans and Lindsay (2010) suggest to choose the kernel size as a

329 function of the typical width of the gullies to detect. In order to capture gullies at different

330 scales, following the suggested approach, nTPI was derived at three different kernel sizes,

331 equal to 10,20 and $30 \mathrm{~m}$ respectively. The kernel sizes of the other indices, i.e. the

332 maximum curvature $c_{\max }$, nMinMax index and the Vosselman index, are instead defined

333 through a calibration procedure detailed in section 4 .

334 The four indices previously defined, which can be considered as markers of 335 presence/absence of the gullies (bottom parts and boundaries), could be used in a typical 336 Boolean framework aimed to the detection of gullies starting from a DEM (i.e. Martínez-

337 Casasnovas, 2003; Evans and Lindsay 2010; Castillo et al., 2014). This approach consists in 338 defining thresholds for each of the different indices, assigning value one (presence of gully 339 feature) to all the pixels which are above (or under) the threshold, and value zero (absence 340 of gully feature) to all the pixels which are under (or above) the threshold and merging the 341 information coming from each single index.

342 However, two types of uncertainties affect this kind of procedure. First, the errors that 343 characterize a LiDAR DEM (i.e. errors deriving from GPS position, inertial measuring unit 344 orientation, and the laser rangefinder) are inevitably propagated to all DEM-derived 345 primary topographic indices such as $n$ TPI, curvature, slope, etc. Second, other uncertainties 346 may arise from the definition of fixed thresholds, which characterizes the classical Boolean 347 approach. When a threshold is fixed, two "similar" values of the analyzed variable can lead 348 to two different outcomes, according to the Boolean approach (true/false or 0/1). 
349 The use of a fuzzy logic approach allows to overcome these disadvantages, by deriving a 350 map that provides a measure of the probability that each single pixel can be part of a gully 351 instead of true/false characterization of the gully. The fuzzy set theory allows soft 352 boundaries and vague landform classes to be explicitly represented, providing more 353 information on landscape structure than discrete and often spatially disjointed Boolean 354 landform classes (Schmidt and Hewitt, 2004; Arrell et al., 2007; Brzank et al., 2008).

355 The fuzzy logic is based on the fuzzy inference, which is a method that interprets the 356 values in the input variable and, based on some set of rules, assigns values to the output 357 variable. The fuzzy logic starts with the concept of a fuzzy set (Zadeh, 1965), which is a set 358 without a crisp, clearly defined boundary. It can contain elements with only a partial degree 359 of membership. A membership function (MF) is a curve that defines how each point in the 360 input variable is mapped to a membership value (or degree of membership) between 0 and 3611 of a specific class.

362 The degree of membership of each pixel to the class of gully (bottom or boundary) was 363 derived by applying specific membership functions to the indices $n$ TPI (for the gully 364 bottom) and $c_{\max }$ and nMinMax (for the gully boundaries). In this way, these continuous 365 variables derived from the LiDAR DEM are transformed into a continuous variable ranging 366 from 0 (no membership to the gully class) to 1 (full membership to the gully class). With 367 regard to the membership function, the S-shape function was selected among the available 368 mathematical equations normally used to depict MF: 


$$
f(x ; a, b)=\left\{\begin{array}{cc}
0 & x \leq a \\
2\left(\frac{x-a}{b-a}\right)^{2} & a \leq x \leq \frac{a+b}{2} \\
1-2\left(\frac{x-b}{b-a}\right)^{2} & \frac{a+b}{2} \leq x \leq b \\
1 & x \geq b
\end{array}\right.
$$

370 where $a$ and $b$ are fixed parameters which locate the extremes of the sloped portion of the 371 curve (Figure 3).

372 The application of S-shape MF to all the five indices layers (three $n$ TPI with different 373 kernel sizes for the gully bottom and nMinMax and $c_{\max }$ for gully boundaries) creates five 374 different raster layers with value ranging from zero (no membership to the gully class) to 375 one (full membership).

376 These raster layers are combined together using specific fuzzy rules. Several fuzzy 377 operators (fuzzy intersection AND, fuzzy union OR, fuzzy algebraic sum, fuzzy algebraic 378 product and fuzzy gamma operator) allow the flexible combination of different input raster 379 layers derived by the application of MFs in a series of steps depicted by Bonham-Carter 380 (1994). In this work two different fuzzy rules, namely fuzzy gamma operator and the fuzzy 381 union OR, were used to combine fuzzy raster layers. The fuzzy gamma operator is derived 382 by combining fuzzy algebraic sum together with fuzzy algebraic product, as follows:

$$
\mu_{\text {gamma }}=\mu_{a l, \text { sum }}^{\gamma} * \mu_{a l, p r o d}^{1-\gamma}=\left[\prod_{i}^{n} \mu_{i}\right]^{\gamma} *\left[1-\prod_{i}^{n}\left(1-\mu_{i}\right)\right]^{1-\gamma}
$$

384 where $n$ is the number of fuzzy raster layers to be combined, $\mu_{\mathrm{i}}$ is the fuzzy membership 385 function for the $i$-th raster layer and $\gamma$ is a parameter chosen between 0 and 1 . Fuzzy gamma 386 is a compromise between increasing tendencies of the fuzzy algebraic sum and the 387 decreasing effect of the fuzzy algebraic product. With the $\gamma$ factor, the decreasing or 
388 increasing tendency can be controlled. When $\gamma$ is equal to $1(0)$ the combination 389 corresponds to the fuzzy algebraic sum (fuzzy algebraic product). The fuzzy union OR 390 operator is similar to the logical union (Boolean OR) and the output membership values are 391 influenced by the maximum values of any of the input membership spatial layers, for any 392 particular location.

393 Figure 4 describes the adopted algorithm, starting from the LIDAR DEM. After indices 394 derivation, a fuzzy gamma operator was used to combine the three fuzzy $n T P I$ (at scale 10, 39520 and $30 \mathrm{~m}$ ) and to combine the fuzzy layers deriving from nMinMax and $c_{\max }$. The output 396 membership layer, deriving from the gamma operation between $n$ MinMax and $c_{\max }$, was 397 combined with the Vosselman filter (Boolean layer) through a classical Boolean intersection 398 AND (i.e. equal to a local product operator). The fuzzy union OR was used to merge 399 membership layers relative to the gully bottom and boundary in order to obtain a single 400 layer representing the degree of membership to the class of gullies. This last operation (i.e., 401 fuzzy union) has been carried out only on pixels representing gully bottom and on 402 boundaries whose reciprocal distances were less than a fixed threshold, $D_{\max }$, here set equal 403 to $10 \mathrm{~m}$. This operation is required to avoid selection of high curvature areas not adjacent 404 to valley bottoms or areas with very low nTPI surrounded by mild curvature.

405 The 'fuzzy' layer of the degree of membership to the class of gullies can be further 406 processed in two alternative ways (Figure 5). The first consists of fixing a threshold of 407 degree of membership ( $\left.T_{\mathrm{dm}}\right)$ and defining as gullies all the pixels whose value exceeds this 408 threshold (Option 1), the second approach, Option 2, is based on techniques of image edge 409 detection (Davis, 1975). 
410 In order to detect edges in an image, several functions are available; these functions

411 search places in the image where the intensity (i.e. pixel values) changes rapidly, using one

412 of these two criteria: a) places where the magnitude of the first derivative of the intensity is

413 greater than some threshold; b) places where the second derivative of the intensity has a

414 zero crossing. Here the Sobel operator (Sobel and Feldman, 1968), which is based on the

415 first criterion and is one of the most used filters to detect edges in images, was used.

416 This operator, which measures the spatial gradient in an image, consists of a pair of $3 \times 3$

417 convolution kernels with one kernel that is simply the other rotated by $90^{\circ}$. These kernels

418 are designed to respond maximally to edges running vertically and horizontally relative to

419 the pixel grid, one kernel for each of the two perpendicular orientations. The kernels can be

420 applied separately to the input image, to produce separate measurements of the gradient

421 component in each orientation (named $G_{\mathrm{x}}$ and $G_{\mathrm{y}}$ ). These can then be combined together to

422 find the absolute magnitude $G$ of the gradient at each point and the angle of orientation $\theta$ of

423 that gradient as follows:

$$
G=\sqrt{G_{x}^{2}+G_{y}^{2}} \quad \theta=\operatorname{arctg} \frac{G_{y}}{G_{x}}
$$

425 In order to identify the gully boundaries, the layer of the magnitude $G$ has to be subject to 426 a further thresholding process, but in this case it is possible to obtain an appropriate 427 threshold value based on an intensity histogram of the image provided by the Sobel 428 operator. The threshold value can be further adjusted by multiplying it with a correction 429 factor $C_{\mathrm{f}}$ in order to increase or reduce the extension of extracted features. 
430 The final outcome of both above-mentioned procedures (Option 1 and 2) is usually a

431 Boolean layer raster ( 1 for gullies pixels and 0 for the background) where several gaps in

432 the lines surrounding the candidate gullies can be observed together with many small pixel

433 clusters scattered in the landscape. These linear gaps and isolated pixel clusters can be

434 removed using "morphological operators" in image analysis (Haralick et al., 1987; Haralick

435 and Shapiro, 1992). These operators, which formally derive from the set theory, are able to

436 process images, or raster layers, based on shapes, and apply a so-called structuring element

437 to an input Boolean image, creating an output image of the same size. In general, the pixel

438 value in the output image is derived by comparing the corresponding pixel value in the

439 input image with its neighbors. By properly choosing the size and shape of the

440 neighborhood, it is possible to build a morphological operation that is sensitive to specific

441 shapes in the input image. The most basic morphological operators are dilation and erosion.

442 Dilation, which combines two sets using vector addition of set elements, adds pixels to the

443 boundaries of objects in an image, while erosion, which is the morphological dual to

444 dilation, combines two sets using the vector subtraction of set elements, and removes pixels

445 on object boundaries. The number of pixels added or removed from objects in an image

446 depends on the size and shape of the structuring element used to process the image. In this

447 case the following sequence of dilation, erosion and filling algorithms were implemented in

448 MATLAB (Gonzales et al., 2009) in order to improve the shape of the extracted gullies 449 (Figure 5):

450 1. dilate the Boolean raster layer using a vertical structuring element followed by a 451 horizontal structuring element. The dilated raster layer closely approximates the 
outline of the candidate gully quite precisely, even if some holes in the interior part of the candidate gully may still remain.

454

455

456

\subsection{Assessment of gully volumes}

472 (2010) but using a more complex interpolation algorithm. Specifically, the procedure 473 involves the following steps: 
474 a) the removal of elevation data within the gully boundary followed by the creation of a $475 \quad$ buffer around the gully perimeter;

476 b) the transformation of pixel values within this buffer zone in points $(x, y, z)$ (i.e. the 477 transformation of a raster structure in a table containing the coordinates $x, y, z$ of $478 \quad$ points belonging to the buffer zone);

479 c) the use of such points to create a "pre-gully" top surface (only for the area covered by 480 the gully) using an hydrological based interpolation method (ANUDEM, Hutchinson, $481 \quad 1988 ; 1989) ;$

482 d) the calculation of the gully volume as the difference between the "pre-gully" top $483 \quad$ surface DEM and the actual DEM;

484 The ANUDEM interpolation was carried out using TOPOTORASTER algorithm 485 implemented in ArcGIS 10.1 using data points (point b), the central drainage line of the 486 gully as streamline feature and excluding elevations value downstream the ending section 487 of the gully.

\section{Method calibration}

The procedural chain proposed in this study involves making choices of many different 491 parameters, which may influence the resulting outcome in terms of accuracy of the 492 identification of gullies.

493 While some of these parameters were pre-set based on previous studies, values of other 494 parameters have to be chosen in order to improve the identifiability of gullies and 495 associated boundaries. 
In particular, the following strategy, based on a mixture of heuristic and algorithmic approaches, has been adopted:

1) The kernel sizes $(\alpha)$ of the three morphometric indices, shown in Figure 4 ( $n$ MinMax, $c_{\max }$ and Vosselman index), were fixed a priori but, for each of these three indices, three different $\alpha$ were chosen starting from the outcomes of previous studies (e.g., Höfle et al., 2013; Tarolli et al., 2012; Johansen et al., 2012), and from an initial qualitative visual analysis. In particular, three different $\alpha$ for each of the three indices were set, i.e. $\alpha$ equal to 3, 5 and $7 \mathrm{~m}$ for $n$ MinMax, $\alpha$ equal to 5, 7 and 9 $\mathrm{m}$ for $c_{\max }$ and, finally, $\alpha$ equal to 3, 5 and $7 \mathrm{~m}$ for the Vosselman index providing an overall number of combinations equal to 27. The Vosselman index, which provides as output a boolen layer, requires also the choice of the slope angle threshold (see section 3.1.4) here set equal to $30^{\circ}$ in order to avoid the exclusion of large areas among those candidate as gullies.

2) The parameters $a$ and $b$ of the S-shape membership function (equation 7 and Figure 3) regarding the indices $n \mathrm{TPI}, n$ MinMax and $c_{\max }$ were chosen equal to the 75th and 95th percentile of the relative variable.

3) The optimal values of the threshold relative to gully fuzzy membership map (Option1) or the threshold of the Sobel filter (Option 2) were robustly defined through an algorithmic procedure that uses a performance metric able to compare survey). 
517 The metric used to compare reference gullies map with the spatial model outcome is

518 derived by the error matrix (Cohen, 1960), which is a square matrix of size $n$ equal to the

519 number of the used classes (here only two classes are used: i.e. gully and no gully). The

520 columns report the reference data (reference gully map) while the rows indicate the model

521 predictions. The generic value $\mathrm{x}_{i j}(i, j=1,2)$ denotes the number of pixel of $i$-th class on the

522 reference map reproduced by the model as $j$-th class. Pixels along the main diagonal

523 represent correct reproduction by the model. The Kappa index, $K$, (Cohen, 1960) was

524 calculated and used as performance metric:

525

$$
\mathrm{K}=\frac{N \sum_{i=1}^{2} x_{i i}-\sum_{i=1}^{2} x_{i+} \cdot x_{+i}}{N^{2}-\sum_{i=1}^{2} x_{i+} \cdot x_{+i}}
$$

526 where $x_{\mathrm{ii}}$ (diagonal cells of the error matrix) represents cases where the predicted value 527 agreed with the observed value, $x_{\mathrm{i}+}$ and $x_{+\mathrm{i}}$ are the marginal totals of row $i$ and column $i$,

528 respectively, and $N$ is the total number of observations (total number of pixels in the area

529 under study). $K$ values provide an objective assessment of model performance. For instance,

530 Fleiss (1981) characterizes $K$ exceeding 0.75 as excellent, $0.40-0.75$ as fair to good, and

531 below 0.40 as poor.

532 The above-mentioned calibration strategy was applied to the gullies present within the

533 SUBAREA-A. For a fixed combination of $n$ MinMax, $c_{\max }$ and Vosselman index, the threshold 534 value of the gullies membership map (Option 1) (or the threshold of the Sobel function -

535 Option 2) were varied within an appropriate range; for each chosen value of the threshold,

536 the procedural chain depicted in Figures 4 and 5 was executed to derive the gullies

537 boundaries (i.e. layer of automatically extracted gullies). The automatically extracted 538 boundaries were compared to those relative to the reference map (i.e. those measured 
539 during the field survey) through the Kappa index. Therefore a $K$ index was then associated 540 to each threshold value at given combination of $\alpha$ of nMinMax, $c_{\max }$ and Vosselman index. As

541 an example, Figure 6a shows the performance, in terms of $K$ index, of the proposed method 542 as a function of the threshold of the gullies membership map (Option 1) for fixed values of

543 Vosselman index, $C_{\max }$ and $\mathrm{nMinMax}$ kernel size $\alpha$ equal to $3 \mathrm{~m}, 7 \mathrm{~m}$ and $5 \mathrm{~m}$, respectively. The

544 analysis shows that the Kappa performance index increases with the threshold value, it

545 reaches its maximum (i.e. 0.876 ) for the threshold value equal to 45 and then decreases. A

546 similar behavior can be observed for the Option 2 case (Figure 6b) where a maximum value

547 of $K$ index (0.846) is achieved for the threshold value equal to 1.4. It is important to point

548 out that in the Option 1 case the performance metric values are always higher than 0.8

549 denoting the good choice of the combination of three morphometric indices, while for the

550 Option 2 a greater sensitivity to the threshold value is observed.

551 A total number of $3 \times 3 \times 3$ combinations among $n$ MinMax, $c_{\max }$ and Vosselman index $(27$

552 combinations) have been explored and, for each combination, the maximum value of the $K$

553 index (i.e. peak of plots similar to those shown in Figure 6) was obtained for the two

554 options. For example, the maximum values achieved with Option 1 for each combination are

555 shown in Figure 7. The figure reports three different subplots for each Vosselman index size

$556(3,5$ and $7 \mathrm{~m})$ and, for each of these subplots, the maximum values of $K$ index as function of

$557 C_{\max }$ for three fixed values of $\alpha$ relative to $n$ MinMax (3m black bar, $5 \mathrm{~m}$ white bar, and $7 \mathrm{~m}$

558 gray bar). One can observe that, generally, the best performances in terms of $K$ index are

559 achieved, for fixed Vosselman index and $c_{\max }$, for the intermediate value of $n$ MinMax $\alpha$ (i.e.

$5605 \mathrm{~m}$ ), even if this behavior is not observed for Vosselman index with a kernel size equal to

$5615 \mathrm{~m}$ and for $c_{\max } \alpha$ equal to 5 and $7 \mathrm{~m}$. In such cases the model performance decreases with 
562 the increase of $n \operatorname{MinMax} \alpha$. The best performance is achieved for the combination of

563 Vosselman index with $\alpha$ equal to $5 \mathrm{~m}, c_{\max } \alpha$ equal to $7 \mathrm{~m}$ and $n \operatorname{MinMax} \alpha$ equal to $3 \mathrm{~m}$.

564 Similar considerations can be provided by the analogous plot for Option 2 which is not 565 shown here for sake of brevity.

566 The use of the best performance combination (i.e. that characterized by the maximum $K$ 567 index) to SUBAREA-A has led to derivation of the gully boundaries shown in Figure 8, 568 shown together with the boundaries surveyed in the field. One can observe that the 569 boundaries of the two gullies are identified by the automatic procedure quite well. A first 570 qualitative assessment of the fit of mapped gullies edges to the field survey is very 571 encouraging suggesting that gully perimeters are well reproduced by the proposed 572 approach. In some points of the study area, where the slope is milder, the proposed 573 methodologies tend to recognize gully boundary with a lower reliability. In order to further 574 confirm the good performances of the proposed method over the SUBAREA-A (already 575 proved by the high value of $K$ index), a quantitative comparison between reference 576 perimeter and automatically identified perimeter was carried out for the two gullies shown 577 in Figure 8 using a simple positional accuracy measure developed by Goodchild and Hunter 578 (1997). The procedure compares a tested linear feature with a reference linear feature by 579 computing the percentage of the length of the tested linear feature, which falls within a 580 buffer of the reference source. This procedure showed that about $70 \%$ of the automatically 581 extracted Box-DX gully perimeter ( $62 \%$ for the Box-SX gully) lies within $1 \mathrm{~m}$ of the "true" 582 position; moreover, the $90^{\text {th }}$ percentile of the buffer width (i.e. the buffer width which 583 determines a coverage percentage of $90 \%$ ) is equal to about $2 \mathrm{~m}$ for Box-DX gully and $2.3 \mathrm{~m}$ 584 for Box-SX gully. Considering that the pixel size of LiDAR DEM used in our procedure is 
585 equal to $1 \mathrm{~m}$ and considering also the uncertainty related to the manual identification of

586 gully perimeter associated to GPS positional error, the accuracy of the gully perimeter

587 identification can be assessed as more than satisfactory. With regard to the possible

588 explanation for differences between reference and extracted gully edges, these could be due

589 to the derivation of LiDAR DEM and its quality (shadowing of non-vertical laser beams,

590 biased filtering of gully rims and data filtering used in the bare soil DEM preparation as

591 highlighted in other previous studies) in addition to the uncertainties which characterize

592 the proposed procedure.

593

594 5. Application to SUBAREA-B and gully volume assessment

595 Once the procedural chain had been calibrated using field surveys contained in

596 SUBAREA-A, it was applied to the larger area, i.e., SUBAREA-B (Figure 2) in order to derive

597 a map of gullies for the Holcombe's branch watershed and assess their characteristics.

598 The application of the procedural chain to SUBAREA-B, using the combination of 599 parameter values that offered the best performance in SUBAREA-A, has led to the 600 derivation of the gully map shown in Figure 9. All the gullies having extension smaller than 601 a threshold area of $40 \mathrm{~m}^{2}$ have been automatically removed from the final map. An analysis 602 of the map yields the area and the boundary length (i.e. perimeter) of gullies together with 603 other derived variables. The empirical distribution function (ecdf) of these derived 604 characteristics are shown in Figure 10. A total number of 122 gullies were identified with 605 an area (Figure 10a) ranging from a minimum of $78 \mathrm{~m}^{2}$ to a maximum of about 5,500 $\mathrm{m}^{2}$, 606 whereas the perimeter ranges from $50 \mathrm{~m}$ to $1,180 \mathrm{~m}$ (Figure 10b). In order to characterize 
607 also the shape of the extracted gullies, the compactness index (Figure 10c), which is given 608 by the ratio between the perimeter $p$ of the gully and the square root of its area $A$ 609 (multiplied by $4 \pi$ ) was estimated. This index ranges from a minimum of 1.23 (most 610 compact gully) to a maximum of about 5 (very elongated gully).

611 The volume and the depth of the derived gullies were estimated following the procedure 612 depicted in Sect. 3.3. Figure 11 shows, by way of example, the different steps followed to 613 assess depth and volume of each gully identified by the proposed algorithm. The gully 614 system used to depict the procedure, which is named Compartment 32 (James et al., 2007) 615 is outside both the SUBAREAS (ULC 430380, 3831890 LRC 430650, 3831720 UTM zone 17 616 N). Specifically, starting from each gully boundary (Figure 11a), the elevation data relative 617 to gully were removed from the original DEM creating an "hole" (Figure 11b); the elevation 618 field of this "hole" was reconstructed through the interpolation method creating the "pre619 gully" top surface (Figure 11c). The map algebra difference operator between the spatial 620 layers containing the "pre-gully" top surface and the original DEM provides the spatial 621 layers of gully depths (Figure 11d) which can be processed using spatial analysis 622 techniques in order to obtain gully volume (function r.volume of GRASS GIS), and the 623 average and maximum depths.

624 Figure 12 shows for the gully identified in the Box-DX of SUBAREA-A (which belongs to 625 SUBAREA-B as well), three cross sections, namely A1-A2, B1-B2 and C1-C2. For these three 626 cross sections Figures 12a, b and c show the original profiles (derived from the original 627 DEM) together with the "pre-gully" profiles (derived with the interpolation procedure). The 628 reconstructed profiles along the transects indicate interpolation procedure and gully filling 629 routine seem to provide a morphologically consistent reconstruction of the elevation field. 
630 The morphometric features of gullies identified within the Holcombe's Branch

631 watershed have been analyzed through their ecdfs shown in Figures 10d, e and f. In

632 particular Figure 10d shows the empirical distribution of volume whose values range from

633 about $30 \mathrm{~m}^{3}$ to $11,180 \mathrm{~m}^{3}$; Figures $10 \mathrm{e}$ and $\mathrm{f}$ show the ecdf for average and maximum depth

634 respectively with values ranging from $0.25 \mathrm{~m}(0.6 \mathrm{~m})$ to $3.7 \mathrm{~m}(6.3 \mathrm{~m})$. The main statistical

635 characteristics of automatically extracted gullies are listed in Table 1 where measures of

636 variability (standard deviation and coefficient of variation), which have been estimated as

637 well, show the strongest spatial variability of volume and area (CV respectively equal to

6381.65 and 1.06) and a greatest homogeneity (low CVs) for depth and compactness index.

639 It is worthwhile to emphasize that, the gully volume assessment can affected by

640 important errors caused by the different uncertainties, which characterize, as previously

641 mentioned, the identification (both manual or automatic) of gully edges (Casalí et al., 2015).

642

643 6. Discussion

644 At the scale of the Holcombe branch watershed (SUBAREA-B, Figure 9), the mapping 645 approach here developed provides a good definition of the spatial pattern of gullies

646 development. The approach proposed surely requires further test to other gullied systems

647 where good quality topographic data is available also allowing for the estimation of gullies

648 volumes, which can be used a sort of proxy of the average gully erosion rates at larger scale

649 (i.e. watershed scale). The application of the method to SUBAREA-B provided the

650 identification as gully candidates of some areas close to the main river channel, which were

651 definitely not gullies but probably bank erosion landforms. Most of these areas were

652 automatically removed because of their small area (less than $A_{s}$ ) while others were 
653 manually removed at the end of automatic procedure. This problem could be solved by 654 removing all pixel clusters adjacent to the main river channel (Castillo et al., 2014) or by 655 introducing another threshold based on the contributing area.

656 One of the most important advantages of the proposed method consists in the removal of 657 many uncertainties, which are related to the definition of fixed thresholds, which 658 characterizes other approaches based on Boolean logic (e.g. Evans and Lindsay, 2010; Höfle 659 et al., 2013; Castillo et al., 2014). Moreover, the normalization of two of the morphometric 660 indices used in the proposed procedure allows for a scale-invariant derivation of gully 661 characteristics that could be valid in other landscapes.

662 Some limitations of the approach must be emphasized: the most important parameters, 663 which are calibrated using data of manual survey (SUBAREA-A), are those relative to the 664 kernel size of the different morphometric indices. It is likely that these parameters are 665 sensitive to the average size of the gully and, for this reason, they should be recalibrated in 666 areas characterized by gully pattern different from those present in the CCZO study area. 667 Moreover, the application of procedural chain might be unsuitable for landscape where the 668 gully edges are not perfectly defined (low contrast in morphometric indices between gully 669 edges and bottom).

670 The evaluation process carried out for SUBAREA-A, based on $K$ index and the positional 671 accuracy measure, could not be applied to SUBAREA-B because of the lack of data due to the 672 great difficulties related to a complete survey over the entire watershed area. For this 673 reason, only in this case, the performances of the procedure are evaluated based on the 674 consistency of the gully sediment yield provided by the proposed method. Specifically, the 
675 obtained values of gully sediment yield are compared with those found in literature in 676 terms of erosion rate. According to the gully mapping of Figure 9 about $3 \%$ of the $4.3 \mathrm{~km}^{2}$ of 677 watershed area is covered by gullies, with an average gully depths equal to about $1.2 \mathrm{~m}$. The 678 total gullies volume, estimated through the proposed methodology, is equal to about $679131,700 \mathrm{~m}^{3}$.

680 An appropriate value of the bulk density is required to quantify the mass of eroded 681 material. Hansen and Law (2006), who analyzed the sediment measured from a 682 discontinuous valley-side gully in the Sumter National Forest, South Carolina, observed that 683 the bulk density of the sediment varies in a time window of about 10 years from a minimum 684 value of $1.4 \mathrm{~g} / \mathrm{cm}^{3}$ to a maximum value of $2.2 \mathrm{~g} / \mathrm{cm}^{3}$. Richter et al. (2000), in work aimed to 685 assess the effect of agriculture and forest regrowth in the nitrogen budget in old-field soils 686 within Calhoun Experimental Forest, measured bulk density for 15 samples at different 687 depths, obtaining an average value of about $1.4 \mathrm{~g} / \mathrm{cm}^{3}$, with lower values close to the 688 ground surface and relatively higher values at the depth of $30 \mathrm{~cm}$.

689 If a range $1.4-2.2 \mathrm{~g} / \mathrm{cm}^{3}$ is assumed for the bulk density of the sediment in the area, the 690 weight of eroded volume from identified gullies is estimated to range between 184,000 and $691290,000 \mathrm{t}$ (or Mg). In order to obtain an average sediment delivery rate, one has to identify 692 the time horizon characteristic of the gully erosion process in the CCZO study area. As 693 mentioned in the Introduction, the Piedmont area of the southeastern US suffered a long 694 period of erosion and gullying primarily due to intensive cotton cultivation. According to 695 Trimble (1974) and Richter and Markewitz (2001), this period ranged from about 1820 to 6961920 with a peak in erosion between 1860 and 1920. A decrease in the erosive processes 
697 was observed after 1920, because of the agricultural decline, as well as a transition of 698 cropland to pasture and forest, and a diffuse actuation of soil conservation practices.

699 Assuming also that these sediments have been eroded by the gullies activity in the last 700190 years, even if the time intensity of this process has been recognized to be non-uniform,

701 it is possible to estimate an average gully sediment delivery rate between 2.25 and $3.55 \mathrm{t}$ 702 ha $^{-1}$ year $^{-1}$ (or Mg ha-1 year-1) for the Holcombe branch watershed.

703 Bennett et al. (2000), Poesen et al. (2003) and De Santisteban et al. (2006) provided 704 some useful statistics regarding soil loss from ephemeral gullies in different areas of the 705 world. For the southeastern US, this value ranges between 1.9 and $17.0 \mathrm{t} \mathrm{ha}^{-1}$ year $^{-1}$ (or Mg $706 \mathrm{ha}^{-1}$ year-1); it is important to point out that these estimated sediment delivery rates are 707 derived at different scale (i.e. at gully scale or at watershed scale). This implies a different 708 support (i.e. area) used to average in space the weight of the measured sediment loss, 709 leading to relatively higher sediment delivery rate when the gully scale is considered, and 710 lower when the rate refers to the watershed scale. The comparison between our 711 assessment, which was carried out at a watershed scale (i.e. $4.3 \mathrm{~km}^{2}$ ), and values from the

712 above-mentioned literature, highlights that our estimate $\left(2.25 \div 3.55 \mathrm{t} \mathrm{ha}^{-1}\right.$ year $\left.^{-1}\right)$ is

713 consistent with in the results of previous studies $\left(1.9 \div 17 \mathrm{t} \mathrm{ha}^{-1}\right.$ year $\left.^{-1}\right)$.

714 Further analyses carried out by Galang et al. (2007) in a $7.5 \mathrm{~km}^{2}$ area close the Sumter

715 National Forest quantified the number and the morphological characteristics of gullies in 716 this area. The values of soil volume eroded by gullies (ranging from 1.9 to $1734 \mathrm{~m}^{3}$ ) and of 717 the corresponding depths (ranging from 1.0 to $5.3 \mathrm{~m}$ ) are compatible with the ecdf of 
718 volumes and depth shown in Figures 10d and 10f, respectively, further confirming the

719 consistency of estimates provided by the present study.

720

\section{7. Conclusions}

722 In this work, an automatic method for gully mapping using topographic data at very high

723 resolution (VHR) has been described and tested. The methodology is based on the joint use

724 of three morphometric indices, used as detection variables, together with other

725 morphometric variables, used only for selection purposes, within a well defined procedural

726 chain which involves different spatial analysis techniques and image analysis algorithms.

727 The main results of the applied methodology have demonstrated its capability to provide an

728 efficient tool for gully detecting, mapping, and analyzing.

729 The fuzzy approach avoided the use of most of the fixed thresholds and of rigid rules

730 needed to identify the gullies. The comparison between automatically extracted gullies and

731 reference gullies (i.e. field survey) allowed the calibration the procedural chain and

732 revealed a high correspondence, in terms of Kappa index, in polygon area values and in the

733 spatial comparison derived by polygon overlay.

734 An interpolation-based algorithm was used to recreate a pre-gully surface which

735 resulted in a reasonable first attempt, and could be improved in the future in terms of

736 computational times and level of automation. The comparison between this pre-gully

737 surface and the actual surface provided the morphological characteristics of the identified

738 gullies (i.e. volume and depth), permitting an estimate of the total sediment volume eroded

739 by gullies over the Holcombe branch watershed. The sediment loss rate, assessed based on

740 assumptions on the value of bulk density and on the temporal interval of the erosive 
741 process, was consistent with previous studies, even if the different uncertainties related to

742 the gullies' edges identification may cause important errors in the determination of gullies'

743 volumes, and in the consequent estimation of the eroded soil at a larger scale (i.e. at

744 watershed scale).

745 With the increasing availability of LiDAR data, this automated technique has potential for

746 applications across a range of environments. Future efforts will focus on implementing a

747 robust version of this algorithm in a single software package (i.e. QGIS). A Python plug-in,

748 able to wrap the different algorithms, could be developed in order to avoid the use of the

749 three different software packages as done in the present work (QGIS, Matlab and ArcGIS).

750

$751 \quad$ Acknowledgements

752 This research was supported by the National Science Foundation (Calhoun Critical Zone

753 Observatory, Award EAR1331846). R. L. Bras acknowledges the K. Harrison Brown Family

754 Chair.

755 


\section{References}

758 Arrell, K.E., Fisher, P.F., Tate, N.J., Bastin L., 2007. A fuzzy c-means classification of elevation

759 derivatives to extract the morphometric classification of landforms in Snowdonia, Wales.

760 Computers \& Geosciences, 33, 10, 366-1381, doi: 10.1016/j.cageo.2007.05.005

761 Baruch, A., Filin, S. 2011. Detection of gullies in roughly textured terrain using airborne

762 laser scanning data. ISPRS J. Photogramm. Remote Sens., 66, 564-578.

763 doi:10.1016/j.isprsjprs.2011.03.001

764 Bennett, S. J., Casali, J., Robinson, K.M., Kadavy, K.C., 2000. Characteristics of actively eroding

765 ephemeral gullies in an experimental channel. Transactions of the ASAE, 433, 641.

766 Blaschke, T., 2010. Object based image analysis for remote sensing. ISPRS J. Photogramm.

767 Remote Sens., 65, 2-16. doi: 10.1016/j.isprsjprs.2009.06.004

768 Blaschke, T., Hay, G.J., Kelly, M., Lang, S., Hofmann, P., Addink, E., Queiroz Feitosa, R., van der

769 Meer, F., van der Werff, H., van Coillie, F., Tiede, D., 2014. Geographic Object-Based Image

770 Analysis - Towards a new paradigm, ISPRS Journal of Photogrammetry and Remote

771 Sensing, 87, 180-191, doi: 10.1016/j.isprsjprs.2013.09.014

772 Bonham-Carter, G.F., 1994. Geographic Information Systems for Geoscientists. Modelling 773 with GIS. Pergamon Press, Oxford, UK.

774 Brzank, A., Heipke, C., Goepfert, J., Soergel, U., 2008. Aspects of generating precise digital

775 terrain models in the Wadden Sea from lidar - water classification and structure line

776 extraction. ISPRS Journal of Photogrammetry and Remote Sensing, 63, 5, 510-528. doi:

777 10.1016/j.isprsjprs.2008.02.002

778 Casalí, J., Giménez, R., Campo-Bescós M. A., 2015. Gully geometry: what are we measuring?,

779 Soil, 1, 509-513, doi:10.5194/soil-1-509-2015

780 Castillo C., Taguas E.V., Zarco-Tejada P., James M.R., Gómez J.A., 2014. The normalized 781 topographic method: an automated procedure for gully mapping using GIS, Earth Surf.

782 Process. Landforms, 39, 2002-2015, doi: 10.1002/esp.3595.

783 Cohen, J., 1960. A coefficient of agreement for nominal scales. Educ Psychol Measure, 20,1, 784 37-46.

785 Daba, S., Rieger, W., Strauss, P., 2003. Assessment of gully erosion in eastern Ethiopia using 786 photogrammetric techniques, Catena, 50, 2-4, 273-291. doi: 10.1016/S0341-

787 162(02)00135-2

788 Davis, L.S., 1975. A survey of edge detection techniques. Computer Graphics and Image

789 Processing, 4, 5, 248-270.

790 De Santisteban, L.M., Casalí, J. and López, J.J., 2006. Assessing soil erosion rates in cultivated 791 areas of Navarre (Spain). Earth Surf. Process. Landforms, 31, 487-506.

792 doi:10.1002/esp.1281 
793 Dialynas, Y.G., Bastola, S., Bras, R.L., Billings, S. A., Markewitz, D., Richter, D., 2016.

794 Topographic Variability and the Influence of Soil Erosion on the Carbon Cycle. Global

795 Biogeochemical Cycles, 30, 5, 644-660. doi: 10.1002/2015GB005302.

796 D'Oleire-Oltmanns, S., Marzolff, I., Tiede, D., and Blaschke, T. 2014. Detection of gully-

797 affected areas by applying object-based image analysis (OBIA) in the Region of Taroudannt,

798 Morocco. Remote Sensing, 6, 9, 8287-8309. doi:10.3390/rs6098287.

799 Eustace, A., Matthew, P., Christian, W., 2009. Give me the dirt: detection of gully extent and

800 volume using high-resolution LiDAR. In: Jones, S., Reinke, K. (Eds.), Innovations in Remote

801 Sensing and Photogrammetry. Springer-Verlag, Berlin Heidelberg, 255-269.

802 Evans, I.S., 1979. An integrated system of terrain analysis and slope mapping. Final report

803 on grant DA-ERO- 591-73-G0040. University of Durham, England

804 Evans, M. and Lindsay, J., 2010. High resolution quantification of gully erosion in upland

805 peatlands at the landscape scale. Earth Surf. Process. Landforms, 35, 876-886. doi:

806 10.1002/esp.1918.Fleiss J.L., 1981. Statistical methods for rates and proportions. 2nd ed.

807 New York: John Wiley; ISBN 0-471-26370-2.

808 Foster, G.R., 1986. Understanding ephemeral gully erosion. Soil Conservation, vol. 2.

809 National Academy of Science Press, Washington, DC, 90-125.

810 Galang, M. A., Markewitz, D., Morris, L. A., Bussell, P., 2007. Land use change and gully

811 erosion in the Piedmont region of South Carolina. Journal of soil and water conservation, 62,

$8123,122-129$.

813 Gallant, J.C., Wilson, J.P., 2000. Primary topographic attributes. In Terrain Analysis:

814 Principles and Applications, Wilson J.P., Gallant J.C. (eds). John Wiley \& Sons: Chichester; pp

815479.

816 Gonzalez, R.C., Woods, R.E. Eddins, S.L., 2009. Digital Image Processing Using MATLAB,

817 Gatesmark Publishing.

818 Goodchild, M.F., Hunter, G.J., 1997. A simple positional accuracy measure for linear features.

819 International Journal of Geographical Information Systems, 11(3), 299-306.

820 Guisan, A., Weiss S.B., Weiss, A.D., 1999. GLM versus CCA spatial modeling of plant species

821 distribution. Kluwer Academic Publishers. Plant Ecology, 143,107-122.

822 Hancock, G.R., Evans, K.G., 2006. Channel head location and characteristics using digital

823 elevation models. Earth Surface Processes and Landforms, 31, 809-824.

824 DOI: $10.1002 /$ esp.1285

825 Hansen, W.F., Law, D.L., 2006. Sediment from a small ephemeral gully in South Carolina. In

826 Proc. Soc. American Foresters National Convention, Fort Worth, Texas.

827 Haralick, R.M., Shapiro, L.G., 1992. Computer and Robot Vision, Vol. I, Addison-Wesley, pp.

828 158-205.

829 Haralick, R.M., Sternberg S.R., Zhuang, X., 1987. Image Analysis Using Mathematical

830 Morphology, IEEE Transactions on Pattern Analysis and Machine Intelligence, 9, 4, 532-550. 
831 Höfle, B., Griesbaum, L., Forbriger, M., 2013. GIS-Based Detection of Gullies in Terrestrial

832 LiDAR Data of the Cerro Llamoca Peatland (Peru). Remote Sens., 5, 5851-5870.

833 doi:10.3390/rs5115851

834 Hutchinson, M.F., 1988. Calculation of hydrologically sound digital elevation models.

835 Proceedings, Third International Symposium on Spatial Data Handling. Columbus,

836 International Geographical Union: 117-33

837 Hutchinson, M.F., 1989. A new procedure for gridding elevation and stream line data with

838 automatic removal of spurious pits. J. Hydrol. 106, 211-232.

839 James, L.A., Watson, D.G., Hansen, W.F., 2007. Using LiDAR data to map gullies and

840 headwater streams under forest canopy: South Carolina, USA, CATENA, 71, 1, 132-144, doi:

841 10.1016/j.catena.2006.10.010

842 Jackson, T.J., Ritchie J.C., White J., Leschack L., 1988. Airborne laser profile data for

843 measuring ephemeral gully erosion. Photogrammetric Engineering and Remote Sensing 54,

844 1181-1185.

845 Johansen, K., Taihei, D., Tindall, D., Phinn, S., 2012. Object-based monitoring of gully extent

846 and volume in North Australia using LiDAR data. Proceedings of the 4th GEOBIA, May 2012,

847 Brazil, 168.

848 Martínez-Casasnovas, J.A., 2003. A spatial information technology approach for the mapping

849 and quantification of gully erosion, Catena, 50, 2-4, 293-308. doi: 10.1016/S0341-

850 8162(02)00134-0.

851 Moore, I.D., Burch, G.J., Mackenzie, D.H., 1988. Topographic effects on the distribution of

852 surface soil water and the location of ephemeral gullies. Transactions of the ASAE, 32, 4,

853 1098-1107.

854 National Center for Airborne Laser Mapping, 2014. Hyperspectral and LiDAR Survey of the

855 Calhoun Critical Zone Observatory, http://calm.geo.berkeley.edu/data/CZOSC2014/

856 Noto, L.V., Bastola, S., Dialynas, Y., Bras, R.L., 2015. Integration of fuzzy logic and image

857 analysis for the detection of gullies in the Calhoun Critical Zone Observatory using airborne

858 LiDAR data. American Geophysical Union Fall Meeting, December 2015, San Francisco, CA.

859 Peasley, B., and Taylor, S., 2009. MER - Soil and land resource condition in NSW: water

860 erosion - monitor and evaluate gully erosion, NSW DECC, Sydney.

861 Perroy, R.L., Bookhagen, B., Asner, G.P., Chadwick, O.A., 2010. Comparison of gully erosion

862 estimates using airborne and ground-based LiDAR on Santa Cruz Island, California,

863 Geomorphology, 118, 3-4, 288-300. doi: 10.1016/j.geomorph.2010.01.009

864 Poesen, J., 1993. Gully typology and gully control measures in the European loess belt. In:

865 Wicherek, S. (Ed.), Farm Land Erosion in Temperate Plains Environment and Hills. Elsevier,

866 Amsterdam, pp. 221-239.

867 Poesen, J., Nachtergaele, J., Verstraeten, G., Valentin, C., 2003. Gully erosion and

868 environmental change: importance and research needs. Catena, 50, 91-133. doi:

869 10.1016/S0341-8162(02)00143-1

870 Poesen, J., 2011. Challenges in gully erosion research. Landform Analysis, 17, 5-9. 
871 Poesen, J., Govers, G., 1990. Gully erosion in the loam belt of Belgium: typology and control 872 measures. In: Boardman, J., Foster, D.L., Dearing, J.A. (Eds.), Soil Erosion on Agricultural 873 Land. Wiley, Chichester, UK, pp. 513-530.

874 Richter, D.D., Markewitz, D. , Heine, P.R. , Jin, V., Raikes, J. , Tian, K., Wells, C.G., 2000.

875 Legacies of agriculture and forest regrowth in the nitrogen of old-field soils. Forest Ecology 876 and Management 138, 233-248. doi:10.1016/S0378-1127(00)00399-6

877 Richter, D.D., Markewitz, D., 2001. Understanding Soil Change: Soil Sustainability over Time 878 Scales of Decades and Centuries. New York, NY: Cambridge University Press.

879 Ritchie, J.C,. Grissinger, E.H., Murphey, J.B., Garbrecht, J.D., 1994. Measuring channel and 880 gully cross-sections with an airborne laser altimeter. Hydrological Processes, 7, 237-244.

881 Roering, J.J., Mackey, B.H., Marshall, J.A., Sweeney, K.E., Deligne, N.I., Booth, A.M., 882 Handwerger, A.L., Cerovski-Darriau, C., 2013. 'You are HERE': connecting the dots with 883 airborne lidar for geomorphic fieldwork. Geomorphology, 200, 172-183. doi:

884 org/10.1016/j.geomorph.2013.04.009

885 Schmidt, J., Hewitt., A., 2004. Fuzzy land element classification from DTMs based on

886

887 geometry and terrain position. Geoderma, 121, 243-256. doi:

888 Shruthi, R.B.V., Kerle, N., Jetten, V., 2011. Object-based gully feature extraction using high 889 spatial resolution imagery, Geomorphology, 134, 3-4, 260-268.

890 10.1016/j.geomorph.2011.07.003.

891 Slatton, K.C., Carter, W.E., Shrestha, R.L., Dietrich, W.E., 2007. Airborne laser swath map892 ping: achieving the resolution and accuracy required for geosurficial research. Geophys. 893 Res. Lett., 34, L23S10. doi: 10.1029/2007GL031939.

894 Sobel, I., Feldman, G., 1968. A 3×3 isotropic gradient operator for image processing, 895 presented at SAIL - Stanford Artificial Intelligence Project.

896 Soil Science Society of America, 2001. Glossary of Soil Science Terms. Soil Science Society of 897 America, Madison, WI, http://www.soils.org/sssagloss/.

898 Soille, P., 1999. Morphological Image Analysis: Principles and Applications, Springer-Verlag, 899 pp. 173-174.

900 Tarolli, P., Arrowsmith, J.R., Vivoni, E.R., 2009. Understanding earth surface processes from 901 remotely sensed digital terrain models. Geomorphology, 113, 1-3. doi:

902 10.1016/j.geomorph.2009.07.005

903 Tarolli, P., Sofia, G., Dalla Fontana G., 2012. Geomorphic features extraction from high904 resolution topography: landslide crowns and bank erosion Natural Hazards, 61, 1, 65-83. 905 doi: 10.1007/s11069-010-9695-2

906 Tarolli, P., 2014. High-resolution topography for understanding Earth surface processes:

907 Opportunities and challenges. Geomorphology, 216, 295-312.

908 dx.doi.org/10.1016/j.geomorph.2014.03.008 
909 Thomlinson, J.R., Bolstad, P.V., Cohen, W.B., 1999. Coordinating methodologies for scaling

910 landcover classifications from site-specific to global: steps toward validating global map

911 products. Remote Sens Environ., 70,16-28.

912 Trimble, S.W., 1974, Man-Induced Soil Erosion on the Southern Piedmont 1700-1970 pp.,

913 Soil Conserv. Soc. Am., Ankeny, Iowa.

914 Valentin, C., Poesen, J., Li, Y., 2005. Gully erosion: Impacts, factors and control. Catena, 63, 915 132-153. doi: 10.1016/j.catena.2005.06.001

916 Vosselman, G., 2000. Slope based filtering of laser altimetry data. In: International Archives

917 of Photogrammetry and Remote Sensing, vol. 33, part B3/2, pp. 935-942.

918 Vosselman, G., Maas, H., 2001. Adjustment and filtering of raw laser altimetry data. Proc.

919 OEEPE workshop on Airborne Laserscanning and Interferometric SAR for Detailed Digital

920 Elevation Models, OEEPE Pub. 40., Stockholm, Sweden.

921 Wood, J., 1996. The geomorphological characterisation of digital elevation models. Ph.D.

922 Thesis, University of Leicester

923 Zadeh, L., 1965. Fuzzy sets. Information and Control, 8, 338-353. 


\section{List of tables}

926 Table 1 - Statistics of automatically extracted gullies for SUBAREA-B: minimum, maximum, 927 mean value, standard deviation (STD) and coefficient of variation (CV) of the six gully 928 characteristics.

929

930 


\begin{tabular}{|l|r|r|r|r|r|}
\cline { 2 - 6 } \multicolumn{1}{c|}{} & \multicolumn{1}{c|}{ Min } & Max & Mean & STD & CV \\
\hline Area $\left(m^{2}\right)$ & 78 & 5152 & 861.8 & 911.6 & 1.06 \\
\hdashline Perimeter $(m)$ & 49 & 1181 & 240.8 & 214.7 & 0.89 \\
\hdashline Compactness index $(-)$ & 1.24 & 4.99 & 2.31 & 0.82 & 0.36 \\
\hline Volume $\left(m^{3}\right)$ & 27.2 & 11179.7 & 1078.9 & 1778.8 & 1.65 \\
\hdashline Average depth $(m)$ & 0.25 & 3.70 & 0.91 & 0.54 & 0.59 \\
\hline Maximum depth $(m)$ & 0.55 & 6.30 & 2.44 & 1.13 & 0.46 \\
\hline
\end{tabular}

932

933 Table 1

934 


\section{List of figures}

936 Figure 1 - LiDAR DEM of the CCZO and two SUBAREA limits used in this study. SUBAREA-A

937 contains the surveyed gullies while SUBAREA-B is relative to Holcombe's Branch watershed

938 (coordinate system UTM zone 17N).

939 Figure 2 - LiDAR DEM relative to: a) SUBAREA-A containing the two gullies surveyed (black

940 line) and the computational boxes (blue line) used to evaluate model performance during

941 the calibration; b) SUBAREA-B is the Holcombe branch watershed.

942 Figure 3 - Fuzzy S-shape membership function with the role of $a$ and $b$ parameters.

943 Figure 4 - Flow chart of proposed gully detection algorithm - part I aimed to the

944 identification of layer of gully class membership values.

945 Figure 5 - Flow chart of proposed gully detection algorithm - part II aimed to the

946 identification of gully boundary through image analysis.

947 Figure 6 - Kappa index as a function of threshold used for gully boundary delineation for

948 fixed values of Vosselman index, $C_{\max }$ and nMinMax kernel size (respectively equal to $5 \mathrm{~m}, 7 \mathrm{~m}$

949 and 3m) using: a) Option 1 and b) Option 2.

950 Figure 7 - Maximum Kappa index achieved for different combination of Vosselman index,

$951 C_{\max }$ and MinMax kernel size using Option 1.

952 Figure 8 -Gullies perimeter provided by field survey (black line) and from the proposed

953 algorithm (purple line) for the two computational boxes (Box-SX and Box-DX) belonging to

954 SUBAREA-A

955 Figure 9 - Gullies identified by the proposed algorithm for SUBAREA-B.

956 Figure 10 - Empirical cumulative distribution function (ecdf) of morphometric

957 characteristics of gullies identified by the proposed algorithm over SUBAREA-B: a) area, b)

958 perimeter, c) compactness index, d) volume, e) average depth and f) maximum depth.

959 Figure 11 - Gully volume assessment. a) Current DEM with gully boundary, b) current DEM

960 after the removing of elevation relative to the gully, c) creation of the "pre-gully" top surface

961 with the interpolation method, and d) difference between "pre-gully" top surface and

962 current DEM (i.e. spatial distribution of gully depths).

963 Figure 12 - a) Gully of the computational BOX DX - SUBAREA-A together with three cross

964 section profiles b), c) and d). 


\section{5}
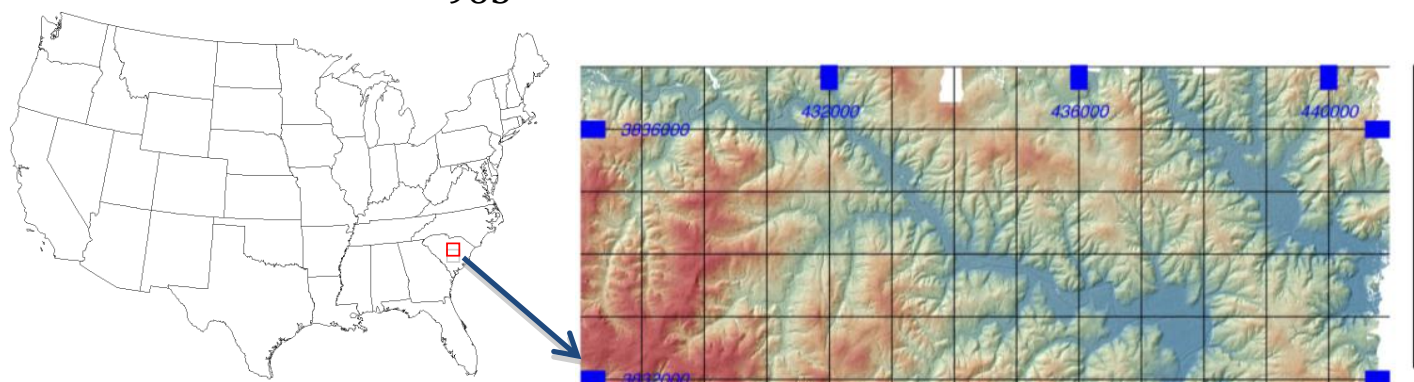

Legend

Subarea A limits

Subarea B limits DEM (m (a.s.l.)
105
125
$\square$
$\square$
165
185

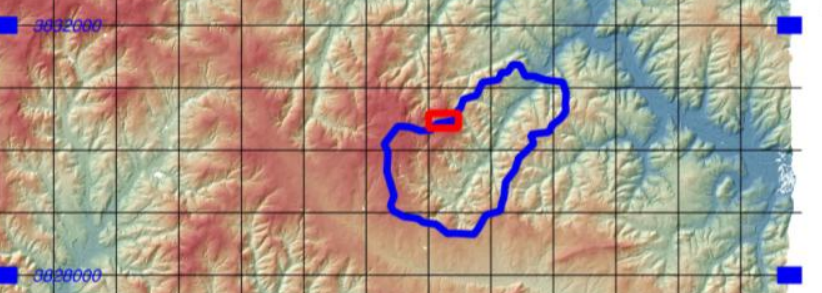

Figure 1

971 


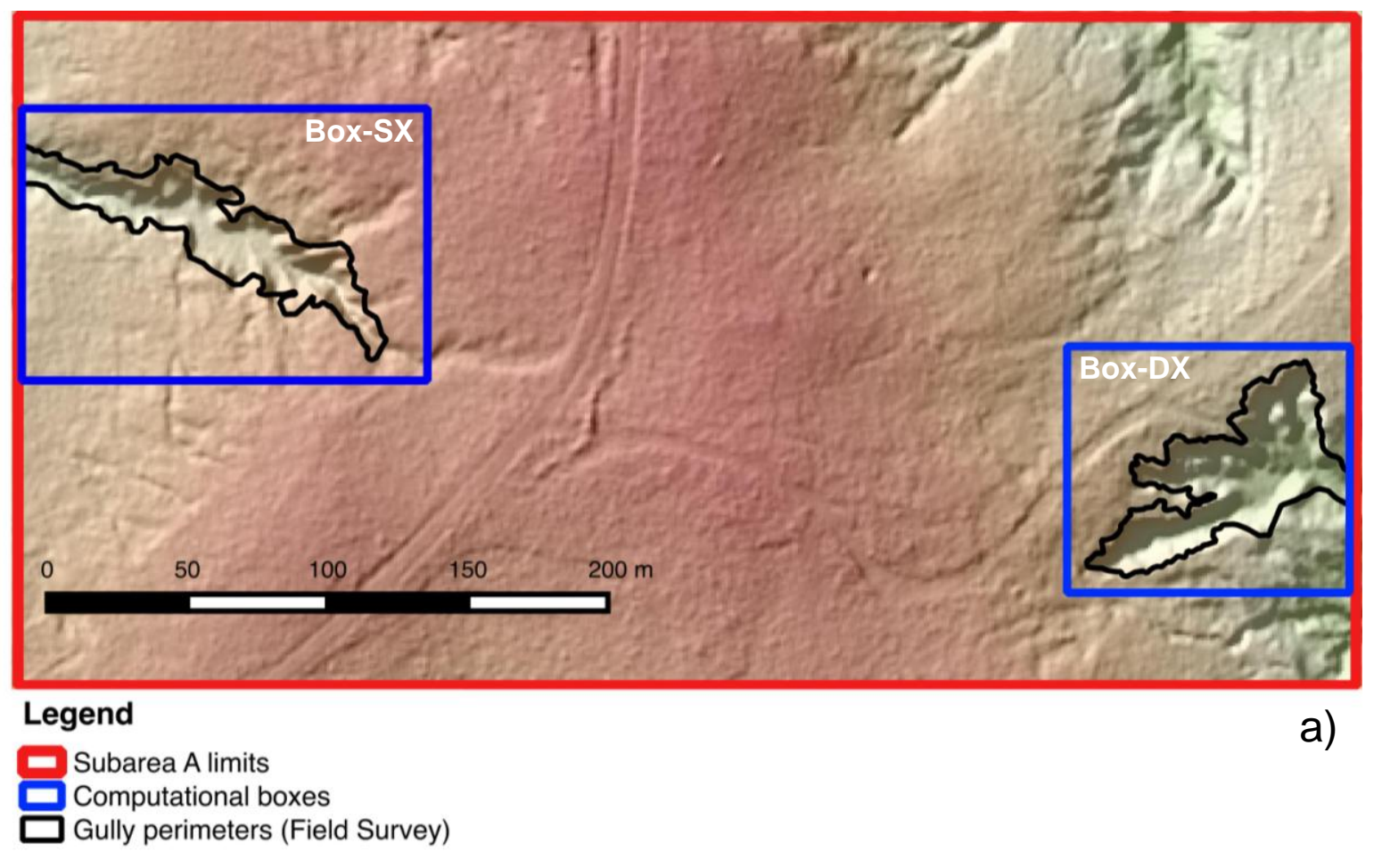

972

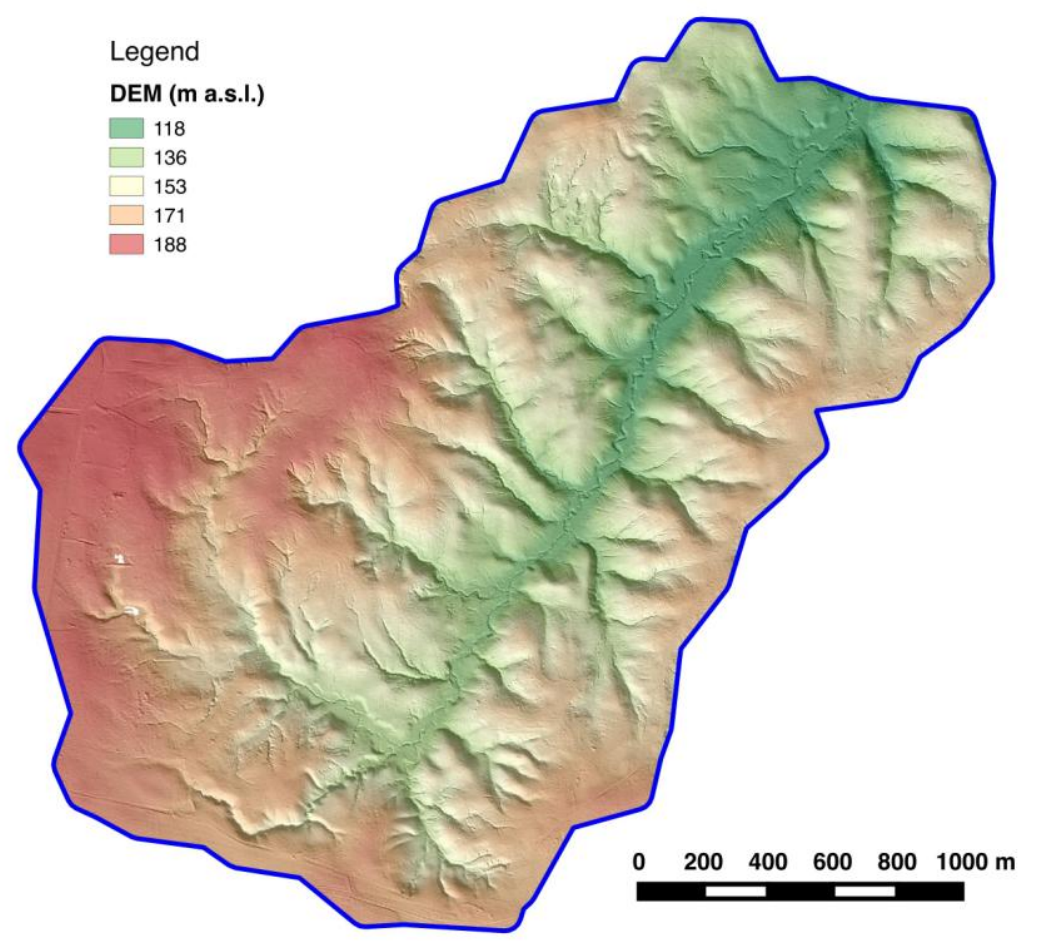

b)

973

974

975 Figure 2

976 


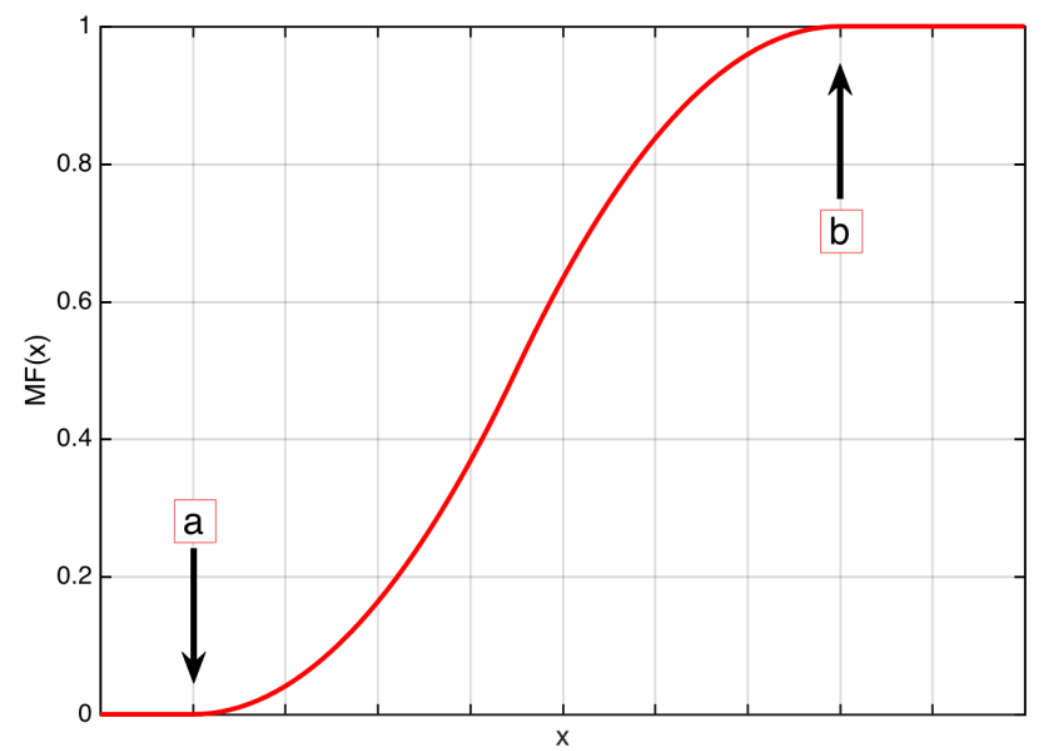

977

978 Figure 3

979 


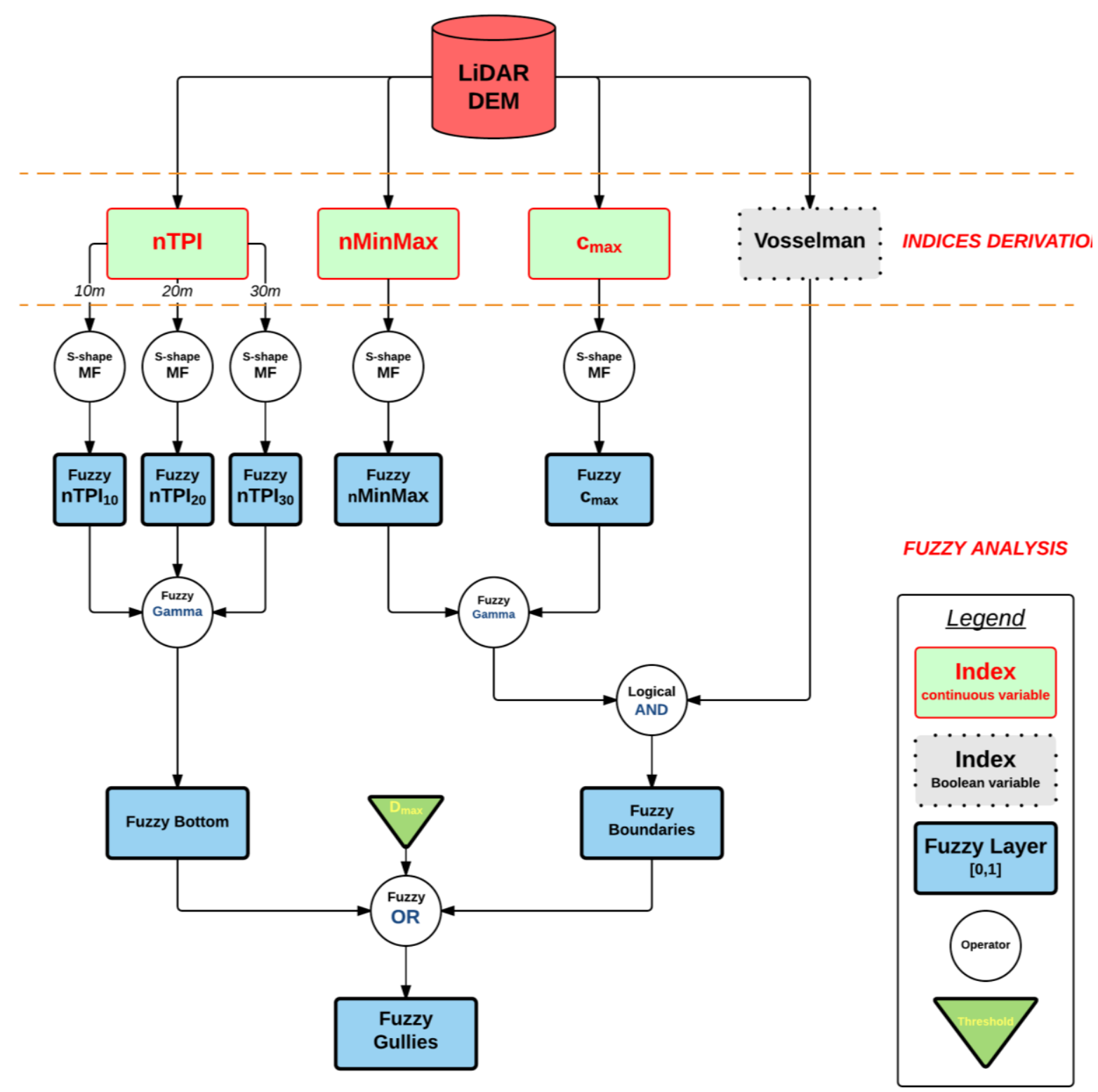

982 Figure 4

983

984 


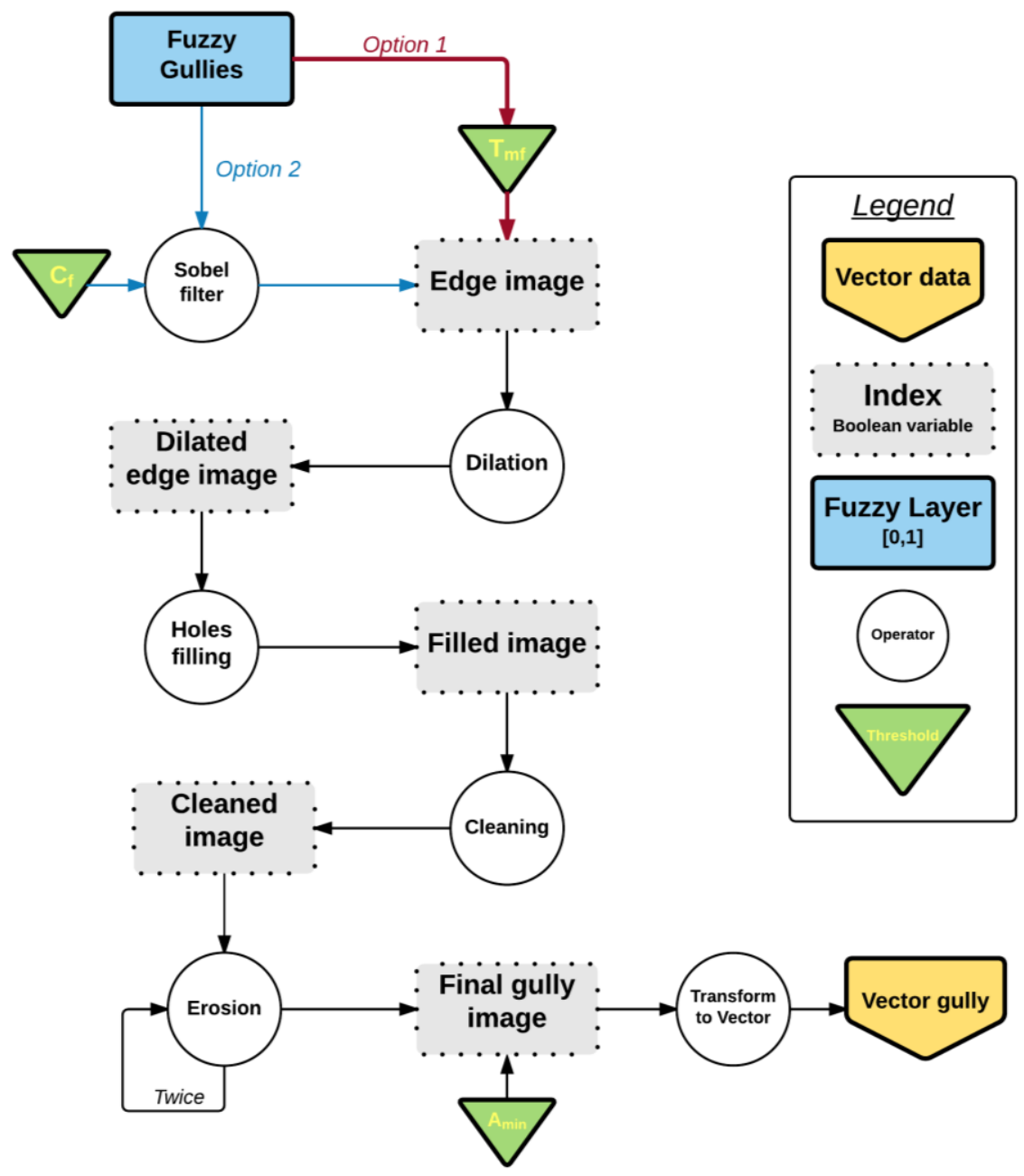

985

986

987 Figure 5

988 

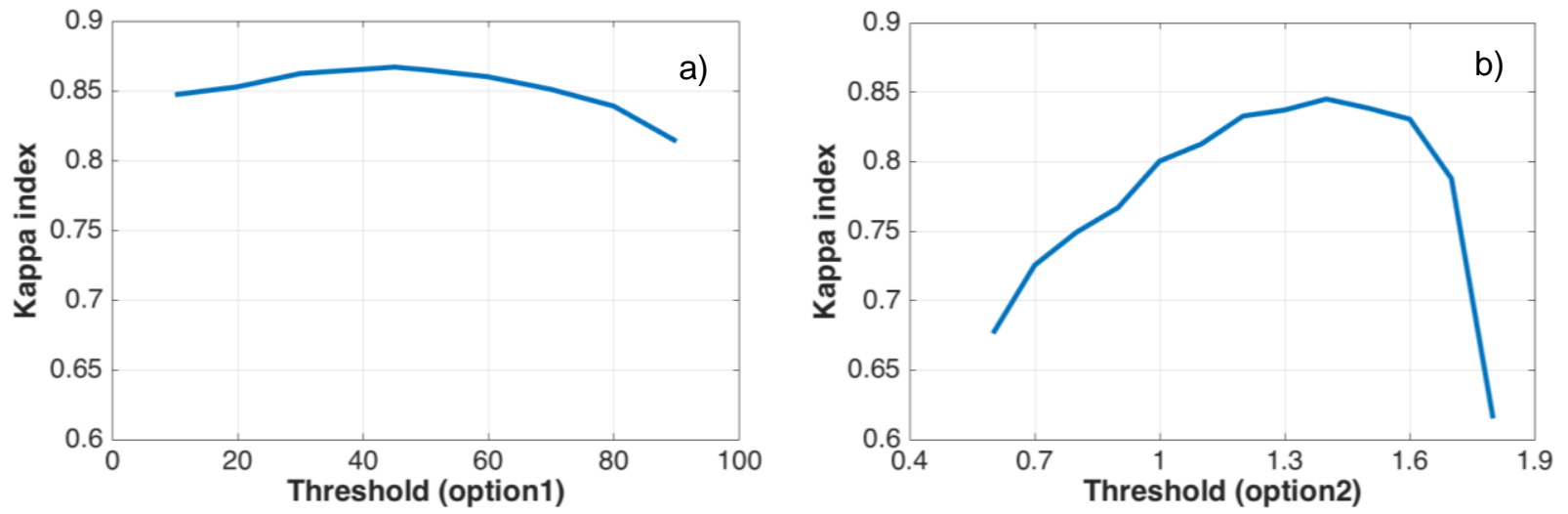

$991 \quad$ Figure 6

992 

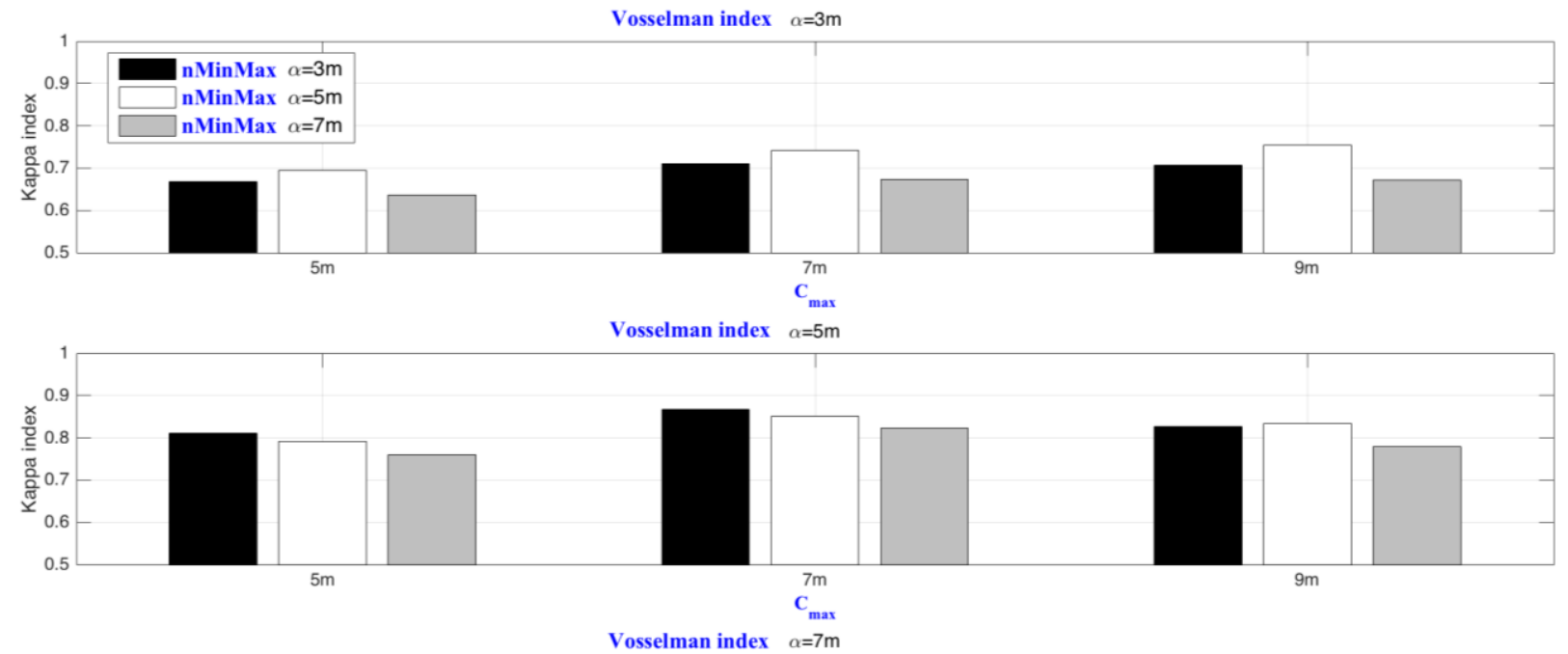

993

994
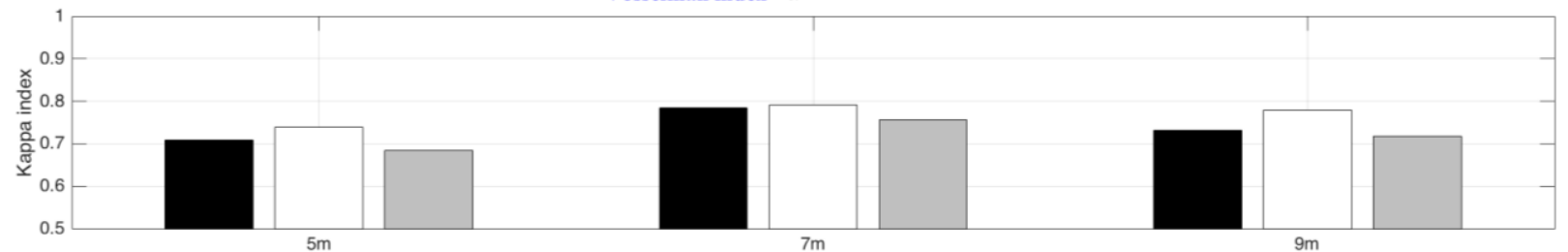

$\mathrm{C}_{\max }^{7 \mathrm{~m}}$

Figure 7

995 
996
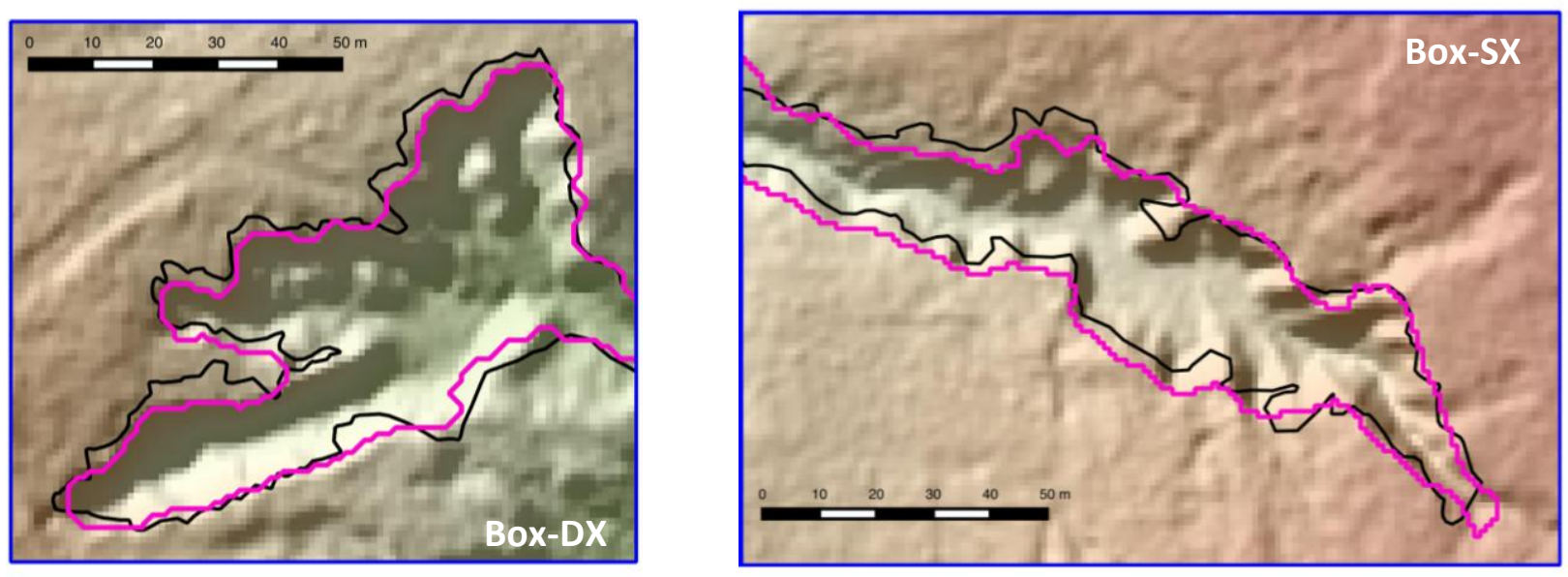

997

998

999 Figure 8

1000 


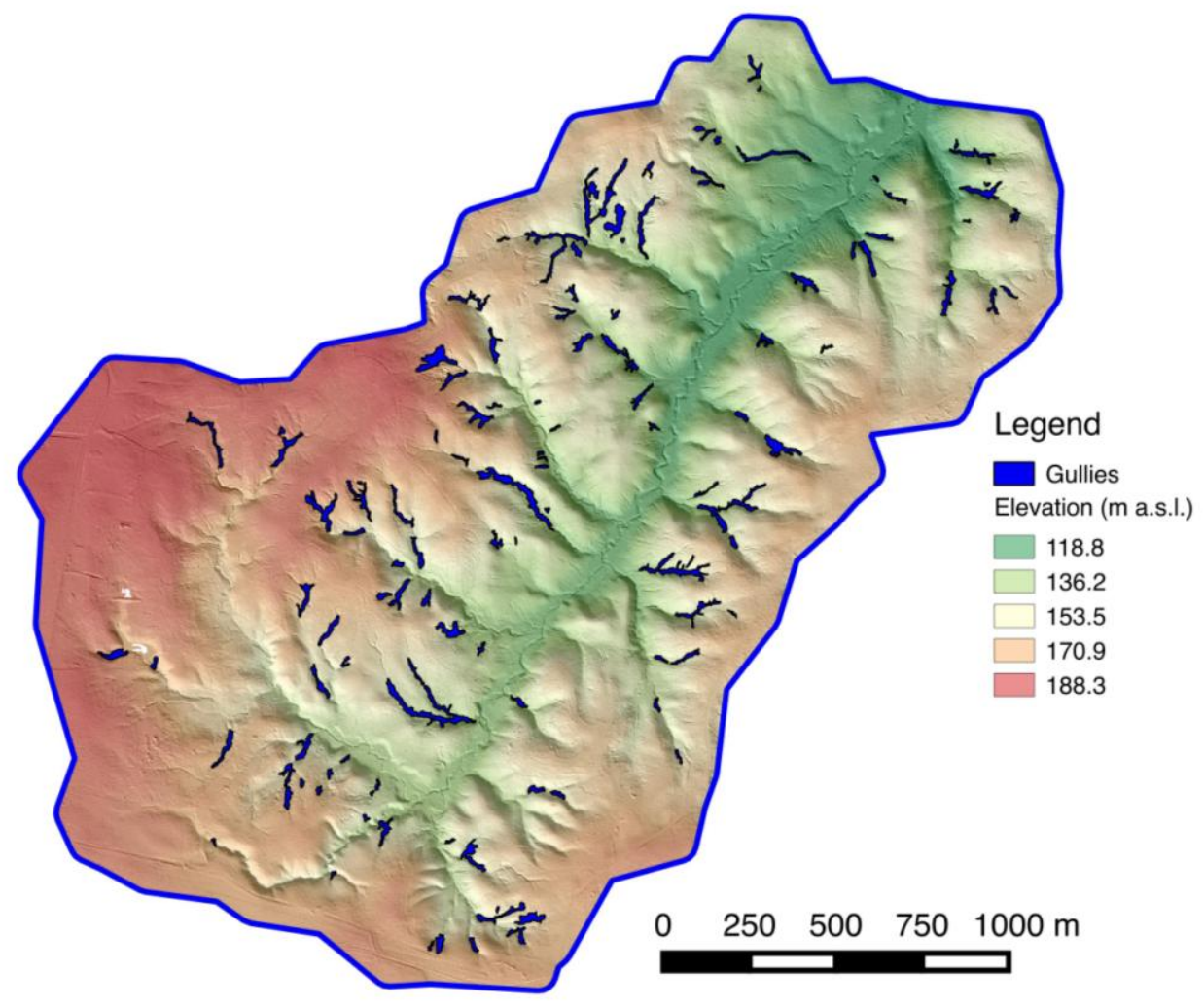

1002

1003

1004

Figure 9

1005 

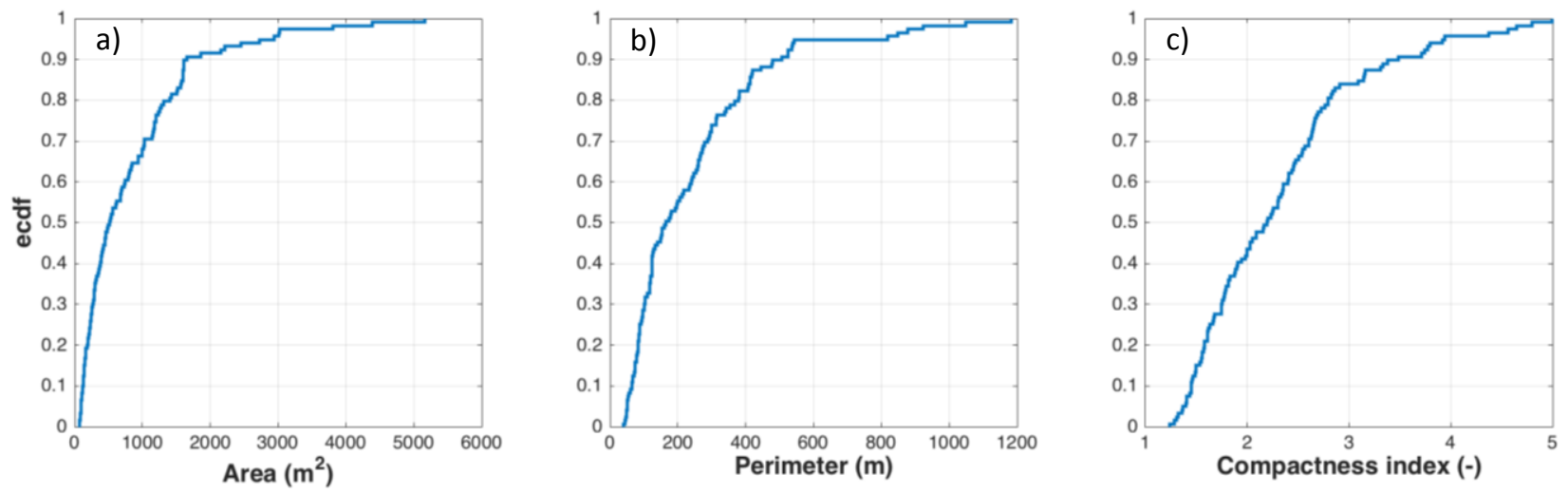

1008

1009
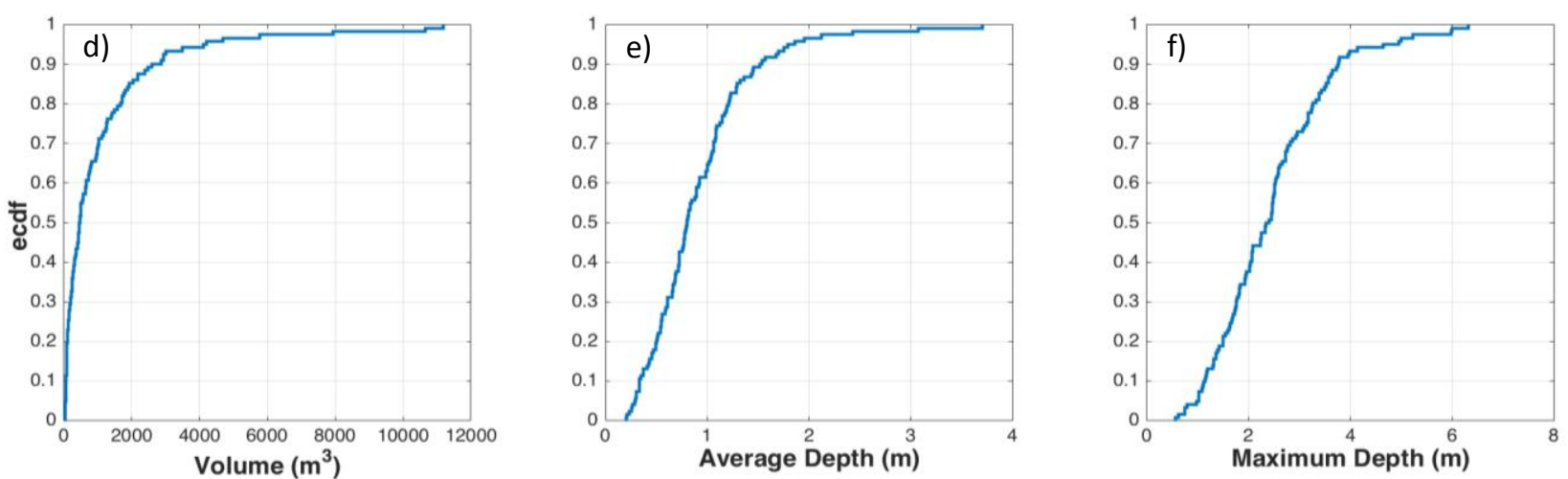

1011

1012

Figure 10

1013

1014

1015 


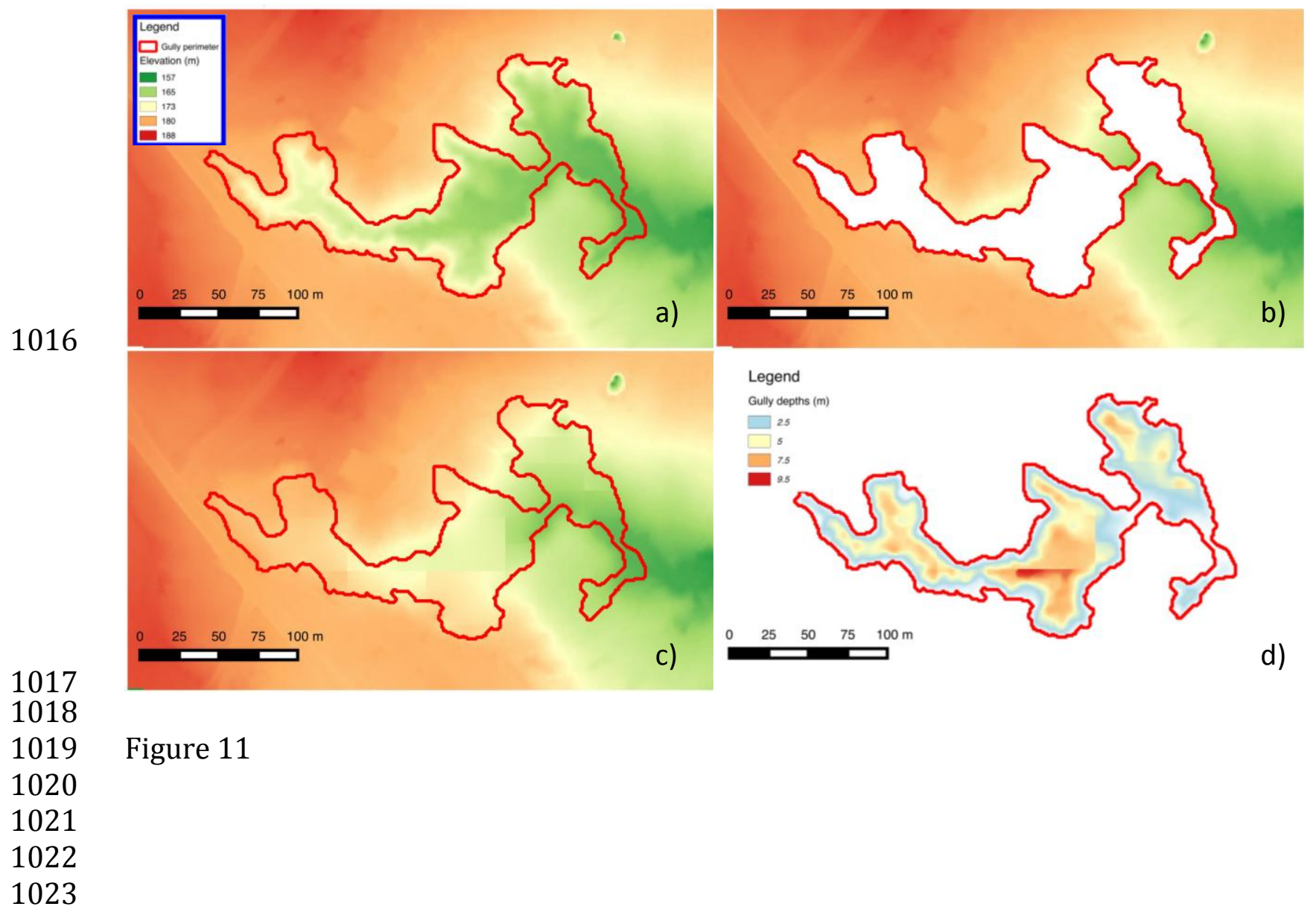




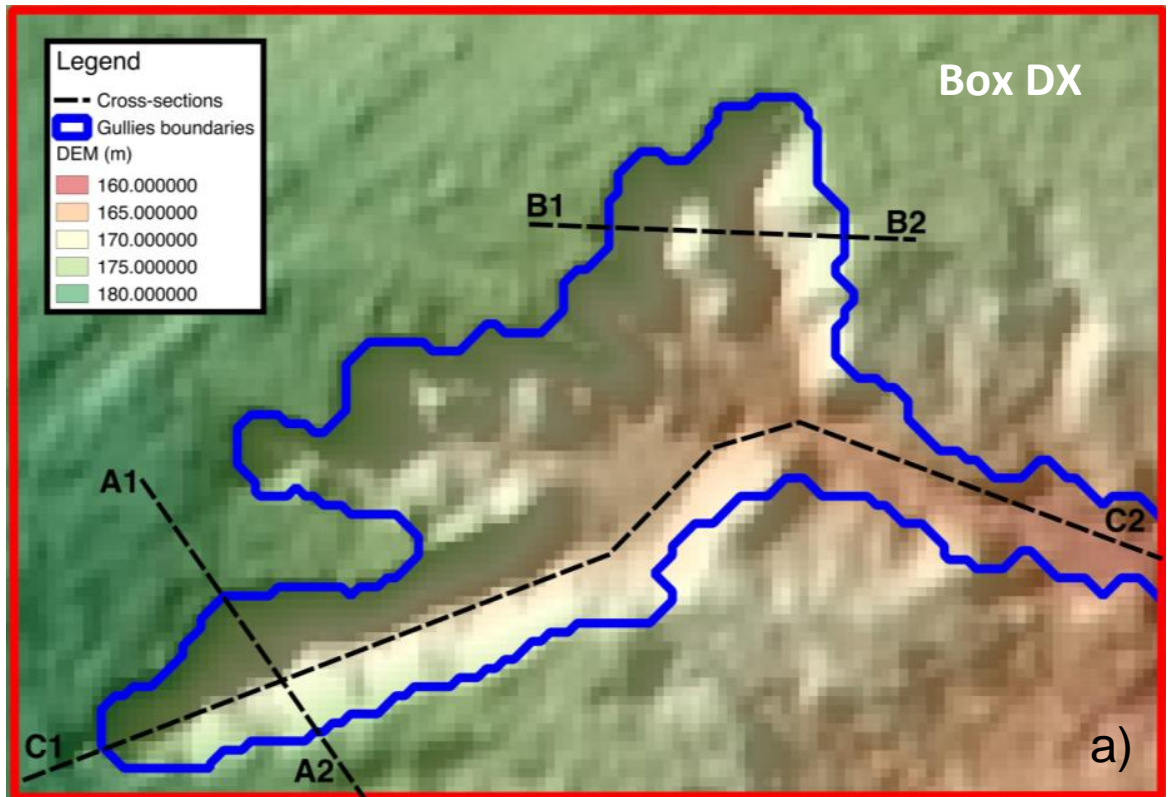

1025

1026

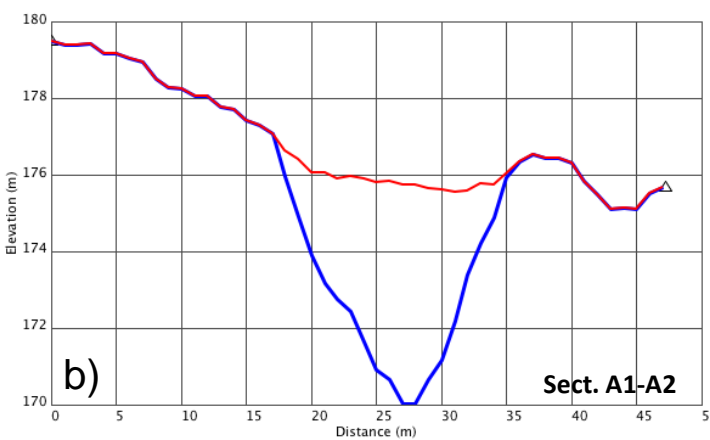

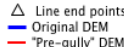

1027
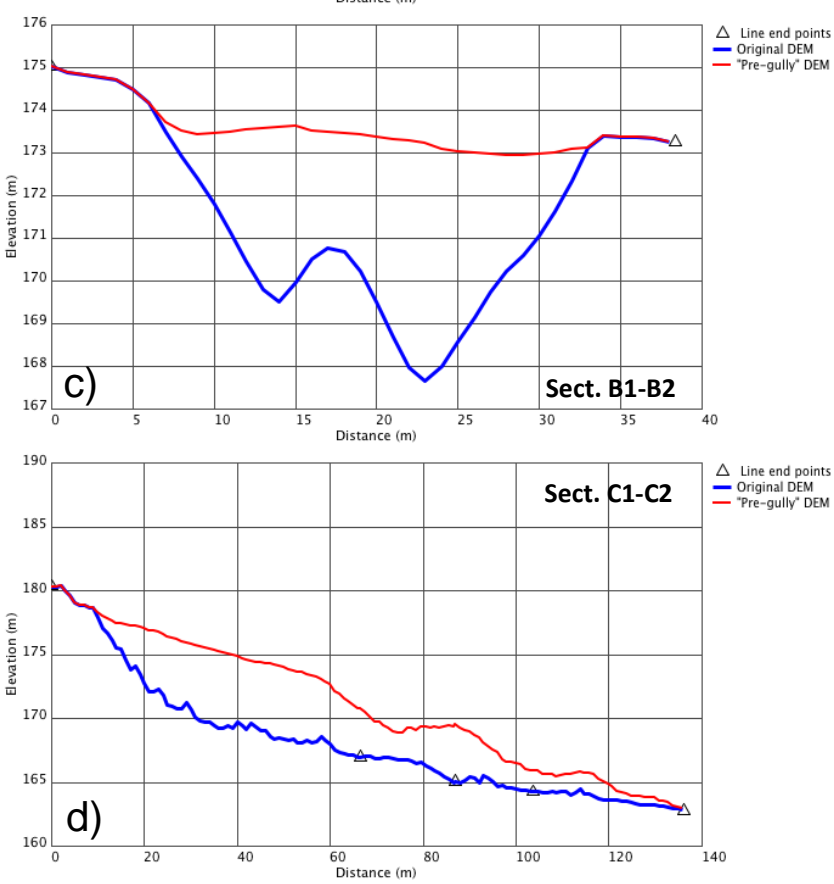

Figure 12 